\title{
Engineered Substrates Reveal Species-Specific Inorganic Cues for Coral Larval Settlement
}

\author{
Mark A. Levenstein,${ }^{1,2+*}$ Kristen L. Marhaver, ${ }^{3 *}$ Zachary A. Quinlan, ${ }^{4}$ Haley M. Tholen, ${ }^{1}$ Lucas Tichy, ${ }^{3,5}$ \\ Joaquín Yus, ${ }^{1,2}$ Ian Lightcap, ${ }^{6}$ Linda Wegley Kelly, ${ }^{4}$ Gabriel Juarez, ${ }^{1}$ Mark J. A. Vermeij, ${ }^{3,7}$ Amy J. Wagoner \\ Johnson ${ }^{1,2 *}$
}

${ }^{1}$ Department of Mechanical Science and Engineering, University of Illinois at Urbana-Champaign, $1206 \mathrm{~W}$ Green Street, Urbana, IL 61801, US, Email: ajwj@illinois.edu

${ }^{2}$ Institute for Genomic Biology, University of Illinois at Urbana-Champaign, 1206 W Gregory Dr, Urbana, IL 61801, US

3 CARMABI Foundation, Piscaderabaai $\mathrm{z} / \mathrm{n}$, PO Box 2090, Willemstad, CW, Email: kristen@marhaverlab.com

${ }^{4}$ Scripps Institution of Oceanography, University of California, San Diego, 8622 Kennel Way, La Jolla, CA 92037, US

${ }^{5}$ Department of Microbiology, Radboud University, Houtlaan 4, 6525 XZ Nijmegen, NL

${ }^{6}$ Center for Sustainable Energy at Notre Dame, University of Notre Dame, Notre Dame, Indiana 46556, US

${ }^{7}$ Department of Freshwater and Marine Ecology, Institute for Biodiversity and Ecosystem Dynamics, University of Amsterdam, Science Park 700, 1098 XH, Amsterdam, The Netherlands

† Present address: Université Paris-Saclay, CEA, CNRS, NIMBE, 91191, Gif-sur-Yvette, FR, Email: mark.levenstein@cea.fr

\section{Abstract}

The widespread loss of stony reef-building coral populations has been compounded by pervasive recruitment failure, i.e., the low or absent settlement and survival of coral juveniles. To combat global coral reef stressors and rebuild coral communities, restoration practitioners have developed workflows to rear and settle vulnerable coral larvae in the laboratory and subsequently outplant settled juveniles back to natural and artificial reefs. These workflows often make use of the natural biochemical settlement cues present in crustose coralline algae (CCA), which can be presented to swimming larvae as extracts, fragments, or live algal sheets to induce settlement. In this work, we investigated the potential for inorganic chemical cues to complement these known biochemical effects. We designed settlement substrates made from lime mortar $\left(\mathrm{CaCO}_{3}\right)$ and varied their composition with the use of synthetic and mineral additives, including sands, glasses, and alkaline earth carbonates. In experiments with larvae of two Caribbean coral species, Acropora palmata (elkhorn coral) and Diploria labyrinthiformis (grooved brain coral), we saw additive-specific settlement preferences (>10-fold settlement increase) in the absence of any external biochemical cues. Interestingly, these settlement trends were independent of bulk surface properties such as surface roughness and wettability. Instead, our results suggest that not only can settling coral larvae sense and positively respond to soluble inorganic materials, but that they can also detect localized topographical features more than an order of magnitude smaller than their body width. Our findings open a new area of research in coral reef restoration, in which engineered substrates can be designed with a combination of organic and inorganic additives to increase larval settlement, and perhaps also improve post-settlement growth, mineralization, and defense. 


\section{Introduction}

Coral reefs are essential aquatic ecosystems that sustain biodiversity and provide tremendous value to the global economy through fishing, tourism, biochemical products, and the protection of shorelines and coastal infrastructure. ${ }^{1-4}$ Unfortunately, these ecosystems have been in decline for decades due to factors including nearshore construction, natural disasters, sewage and fertilizer pollution, overfishing, disease outbreaks, and increasing sea surface temperatures..$^{5-8}$ One of the primary mechanisms by which reefs can recover from such large-scale disturbances is through the sexual propagation of foundational reefbuilding coral species. ${ }^{9-10}$ The operational term for this process is "coral larval recruitment." During the process of coral reproduction and recruitment, corals first release either swimming larvae or gametes that develop into larvae. These larvae then travel distances ranging from centimeters up to hundreds of kilometers in search of a suitable location to settle, i.e., where they can attach to the reef, undergo metamorphosis, mineralize a skeleton, and eventually mature into an adult coral colony. ${ }^{11-13}$ However, natural recruitment has an exceptionally low success rate, which has fallen to near zero due to human pressures. ${ }^{14-15}$ Thus many research and restoration efforts now focus on better understanding this process and developing practical interventions. ${ }^{16-17}$

Larval navigation and settlement behavior are influenced by a variety of natural cues, the best known being the biochemical signals arising from mineralized crustose coralline algae (CCA) and CCA-associated bacteria. ${ }^{18-20}$ Researchers and restoration practitioners routinely harness these cues to induce larval settlement in the laboratory. For instance, artificial substrates intended for settlement are often conditioned for months on a natural reef or in flow-through aquaria in order to develop algal and microbial films. ${ }^{21-24}$ Alternatively, higher concentrations of biochemical cues are presented to larvae by placing fragments or powders of CCAs directly onto settlement substrates, ${ }^{25-27}$ by introducing soluble extracts isolated from CCAs into settlement containers, ${ }^{25,} 28-30$ or by incorporating CCA extracts into solid resins. ${ }^{20}$, 31-32 Once larvae have settled and matured into juvenile corals over several weeks to months in protected aquaria or nurseries, they are then outplanted back to degraded reefs to bolster restoration efforts.

Although not yet routinely applied by coral restoration practitioners, there are also many physical cues that can influence the behavior of marine larvae. These include factors such as the specific sounds, ${ }^{33}$ light regimes, ${ }^{34}$ and hydrodynamic conditions of reefs, ${ }^{35}$ as well as the properties of natural or artificial substrate materials. ${ }^{36-38}$ In particular, many studies have noted that coral larvae and other fouling organisms display settlement preferences based on substrate surface topography..$^{39-41}$ These observations have often been rationalized using Attachment Point Theory, which states that fouling organisms generally prefer substrates with surface features or roughness on a length scale that maximizes the settler-substrate contact area, i.e., on a length scale close to the organism's body width. ${ }^{42-43}$ Some studies have also reported settlement preferences based on substrate color ${ }^{22,44}$ or wettability. ${ }^{39,45}$ However, like studies of surface roughness, these studies have focused on extrinsic and/or bulk (average) properties of the substrate rather than the intrinsic properties of the underlying material.

As reef-building organisms, corals are complex arrangements of both soft organic tissues and hard bioinorganic skeletons. Thus, it is plausible that corals have evolved to seek out specific inorganic chemicals or materials during the larval stage that would indicate whether a location will be favorable for mineralization and skeletal attachment and support. Indeed, a growing number of field studies have demonstrated that larval settlement rates of calcifying marine invertebrates vary on common structural materials (e.g., concrete, stainless steel). ${ }^{46-47}$ Further work has assessed the ability of different materials 
to promote the growth of settlement-inducing algae and microbial communities. ${ }^{48-49}$ However, to our knowledge, larval settlement cues related solely to inorganic material composition have not yet been investigated systematically.

Here, we present the development of artificial substrates containing potential inorganic larval settlement cues and the discovery of species-specific settlement preferences in the absence of CCA or other biochemical settlement inducers. We produced lime mortar $\left(\mathrm{CaCO}_{3}\right)$ substrates with a range of additivesincluding sands, glasses, and carbonates of alkaline earth elements that are essential to coral mineralization-to determine whether larvae exhibit preferences to settle on particular materials. In randomized settlement choice experiments with larvae of the Caribbean elkhorn coral Acropora palmata and grooved brain coral Diploria labyrinthiformis, larvae distinguished between substrates containing different inorganic additives and different concentrations of a glass fiber additive. Analysis of substrate properties using 3D laser scanning confocal microscopy and direct contact angle measurements revealed no correlation between settlement preference and average surface roughness or wettability. Instead, our results support the existence of more localized surface recognition capabilities in coral larvae. As well, we identify a possible mechanism driving the larval settlement behavior in our experiments, specifically the release of ions from soluble strontianite $\left(\mathrm{SrCO}_{3}\right)$ and silica $\left(\mathrm{SiO}_{2}\right)$ additives that were incorporated into substrates.

\section{Experimental Section}

\section{Study Sites and Species}

Larval settlement experiments were conducted on the southern Caribbean island of Curaçao (Fig. 1a) with two species of hermaphroditic broadcast spawning coral, Acropora palmata (elkhorn coral) and Diploria labyrinthiformis (grooved brain coral). Gametes were collected from two sites on the leeward coast of the island: A. palmata from Sea Aquarium ( $12^{\circ} 4^{\prime} 59^{\prime \prime} \mathrm{N}, 68^{\circ} 53^{\prime} 43^{\prime \prime} \mathrm{W}$; Fig. $\left.1 \mathrm{~b}\right)$ and $D$. labyrinthiformis from the Water Factory (also known as Koredor; $12^{\circ} 6^{\prime} 34^{\prime \prime}$ N, 68 $57^{\circ} 23^{\prime \prime}$ W; Fig. 1c).

\section{Gamete Collection and Larval Care}

Broadcast spawning hermaphroditic corals, including those studied here, typically reproduce in mass spawning events that occur during a small number of nights following the full moon each month. The timing of spawning (including month, number of nights, and timing relative to both the full moon and local sunset) is species-dependent. ${ }^{50}$ On each night of spawning, adult coral colonies of the species studied here (Fig. 1d and 1e) release buoyant bundles of eggs and sperm that float upward and break apart at the sea surface due to wave action. This allows eggs and sperm from several hermaphroditic parent colonies to mix and cross-fertilize. The resulting embryos then develop into motile larvae that navigate ocean currents over days to weeks in search of a suitable settlement site. ${ }^{12}$ For larval studies and larva-based coral propagation, gametes are usually collected at the time of spawning and reared into larvae in a controlled environment. 

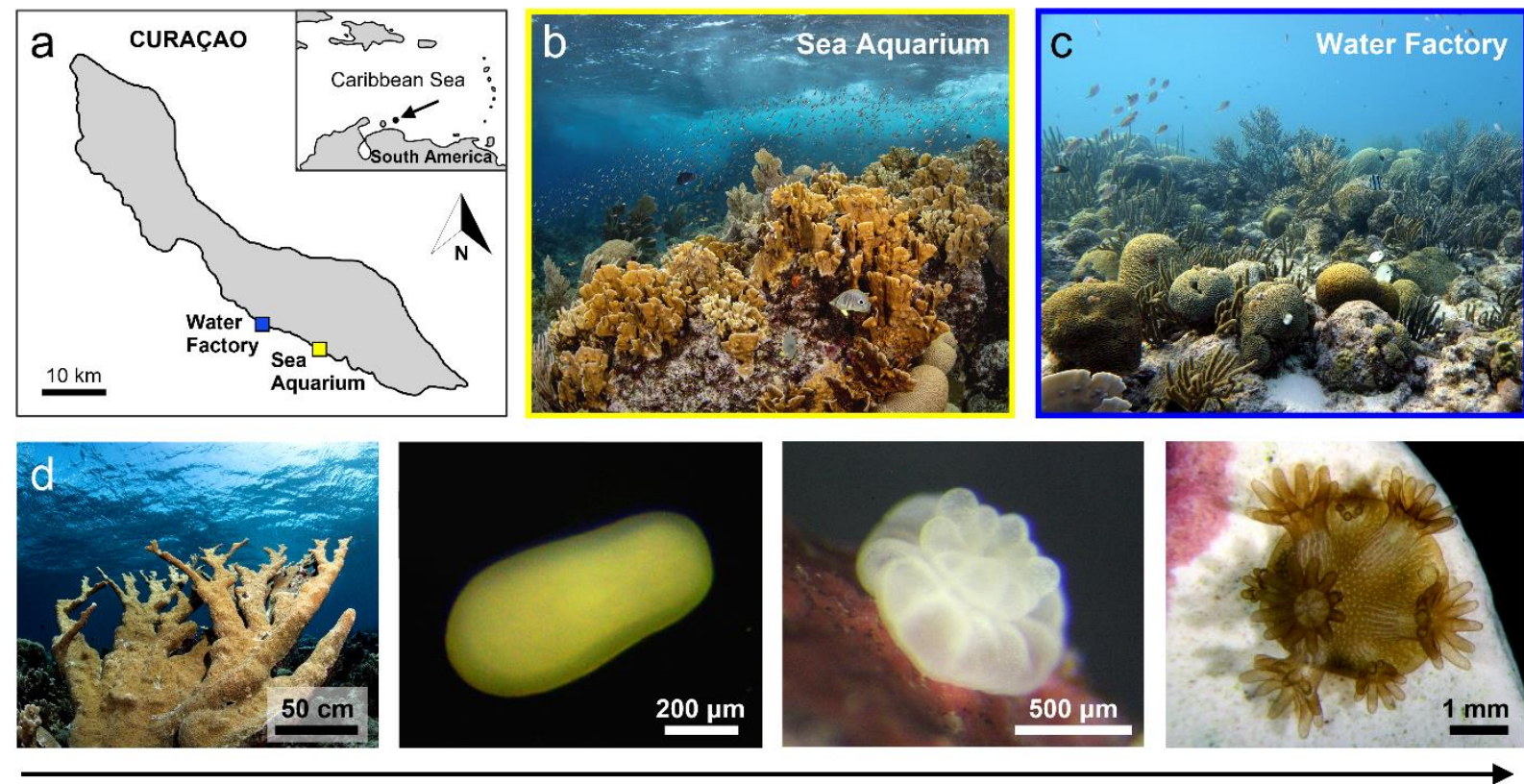

Adult A. palmata

Day 4 - Larva

Week 2 - Settler

Week 24 - Juvenile
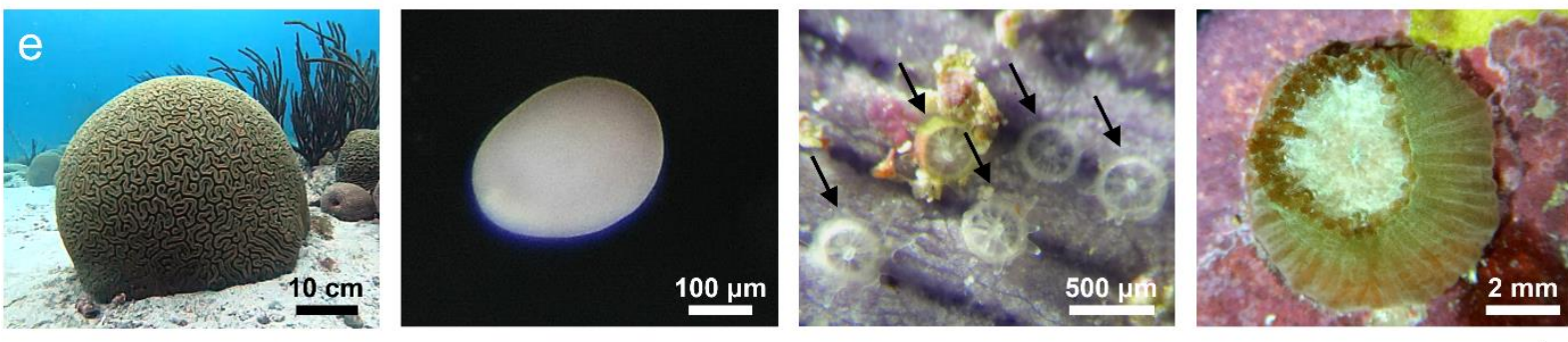

Adult $D$. labyrinthiformis

Day 2 - Larva

Week 6 - Settlers

Week 40 - Juvenile

Figure 1. Study site and species. (a) Map of the island of Curaçao showing the location of source reefs where coral gametes were collected for this study: (b) Sea Aquarium and (c) Water Factory. The inset displays the location of Curaçao within the southern Caribbean Sea. Photographs of the early life history of the broadcast spawning Caribbean coral species (d) Acropora palmata and (e) Diploria labyrinthiformis showing a reproductive adult, motile larvae, primary polyp settlers, and older juveniles. Scale bars were approximated based on field measurements. Photo credits: Sea Aquarium and adult A. palmata photos, Zach Ransom; A. palmata larva photo, Valérie Chamberland; Adult D. labyrinthiformis photo, Evan Culbertson; Remaining photos, Marhaver Lab.

For this study, gamete collection and subsequent larval rearing were based on previously established methods, ${ }^{23,27,51}$ which are summarized here. In August of 2019, A. palmata gametes were collected during the spawning event occurring 1 day after the full moon from approximately 10 adult colonies situated between $2 \mathrm{~m}$ and $8 \mathrm{~m}$ depth. $D$. labyrinthiformis gametes were collected 11 days after the full moon from 8 adult colonies situated between $5 \mathrm{~m}$ and $12 \mathrm{~m}$ depth. $D$. labyrinthiformis gametes were also collected 10 days after the full moon in May 2019 for preliminary settlement experiments. Within 1 hour of collection, gametes from all colonies were mixed in $1 \mathrm{~L}$ polycarbonate fat separators with filtered seawater (FSW) and allowed to fertilize. All seawater was pre-treated using a succession of stacked sediment filters with pore sizes of $50,20,5$, and $0.5 \mu \mathrm{m}$, consecutively $\left(\mathrm{H}_{2} \mathrm{O}\right.$ Distributors, Marietta, GA). After 1 hour of 
fertilization, the embryos were rinsed with an excess of FSW to remove any remaining sperm and aliquoted into several $1 \mathrm{~L}$ food-grade polystyrene bins to achieve a final density of $\leq 2 \mathrm{embryos} / \mathrm{mL}$. The embryos were incubated in the bins overnight to develop into larvae, after which unfertilized eggs were removed by pipetting or by rinsing the larvae over a $150 \mu \mathrm{m}$ nylon mesh filter. Larval health and motility were maintained by performing container and water changes every 2 days until the start of substrate settlement experiments.

\section{Selection of Substrate Base Materials}

At the outset of this project, we tested a range of materials that could serve as a base material for fabricating coral settlement substrates, which could be subsequently modified to investigate larval preferences. The candidates for base material were selected based on their availability and cost, ease of fabrication and/or modification, and for a diversity of compositions. The first material selected for testing was lime mortar, a calcite $\left(\mathrm{CaCO}_{3}\right)$-based material produced from hydrated lime (also known as kalkwasser powder by aquarists) that is used in the restoration of historic buildings. ${ }^{52}$ Notably, coral skeletons are also made of $\mathrm{CaCO}_{3}$, although in its aragonite form. The second material selected was calcium phosphate (CaP), the primary mineral component of vertebrate bone. Our group has expertise in additive manufacturing of CaP scaffolds for bone regeneration, ${ }^{53-54}$ and this represented an opportunity to transfer knowledge from tissue engineering to coral reef restoration. In addition to these Ca-based mineral systems, two engineered polymers were also selected. The first was poly(methyl methacrylate), or acrylic, which is used widely in the aquarium hobby. Anecdotal observations also suggested that the hydrophobicity and smoothness of this material might promote attachment by the hydrophobic coral larvae and/or discourage algal attachment. The final base material selected was polydimethylsiloxane (PDMS), a transparent moldable elastomer often utilized in microfluidics and microfabrication. ${ }^{55}$ The use of PDMS in antifouling applications also suggested a potential benefit to settling coral larvae if this material promoted coral attachment and/or inhibited algal fouling. ${ }^{40}$

\section{Lime Mortar Substrate Preparation}

Lime mortar substrates were fabricated from an unaged lime putty prepared by mixing an aquarium-grade kalkwasser powder $\left(\mathrm{CaOH}_{2}\right.$, ESV Aquarium Products) and fresh tap water into a paste by hand (1:1 ratio powder to water by mass). The mortar was cast into cylindrical disks of nominal $8 \mathrm{~mm}$ thickness and 33 $\mathrm{mm}$ diameter using flexible silicone molds. After 18 hours, the substrates were removed from the molds and placed in a sealed $50 \mathrm{~L}$ glove bag (model 108D, Glas-Col) with 200-250 g of dry ice. As the dry ice sublimes, it produces gaseous $\mathrm{CO}_{2}$ that increases the rate of carbonation (i.e., conversion of $\mathrm{Ca}(\mathrm{OH})_{2}$ to $\mathrm{CaCO}_{3}$ ), which sets the mortar more rapidly. Substrates remained in the glove bag for 7 days with daily replacement of dry ice and removal of condensation to allow the carbonation reaction to continue. After carbonation, each substrate weighed approximately $7.30 \pm 0.34 \mathrm{~g}$ and had a density of $1.07 \pm 0.05 \mathrm{~g} \mathrm{~cm}^{-3}$ (mean \pm standard deviation; based on $n=20$ measured samples). A description of the fabrication and preparation of additional substrate types, which were used in preliminary experiments to select a base material, is provided in the Supporting Information. 
A range of particulate additives were mixed into the base mortar in order to investigate their effect on larval settlement. The additives were: aragonite sand (\#0, Nature's Ocean), quartz sand (All Purpose Sand, Quikrete), glass fibers (1/32" milled glass fibers, \#38, Fibre Glast), bioactive glass (type 45S5, XL Sci-Tech), dolomite $\left(\mathrm{CaMg}\left(\mathrm{CO}_{3}\right)_{2}, \mathrm{KAL}\right)$, and strontianite $\left(\mathrm{SrCO}_{3}, \geq 98 \%\right.$, Sigma-Aldrich) (Fig. S1 and S2). Additive powders were ground with a mortar and pestle and mixed with the kalkwasser powder before adding water. The concentration of all additives was fixed at $10 \mathrm{wt} \%$ of the dry mixture unless otherwise noted. Strontianite was included at $8 \mathrm{wt} \%$ to match the number of moles of $\mathrm{Sr}$ to the number of moles of $\mathrm{Mg}$ in substrates containing $10 \mathrm{wt} \%$ dolomite. Additionally, substrates with a combination of dolomite and strontianite (Dol/Str) were prepared at $5 \mathrm{wt} \%$ dolomite and $4 \mathrm{wt} \%$ strontianite. The final mass fraction of the additives in the carbonated substrates was $\sim 26 \%$ lower than the mixed concentration, because $\mathrm{CaCO}_{3}$ has a greater molar mass than $\mathrm{Ca}(\mathrm{OH})_{2}$ and thus the substrates gain weight during carbonation. The compositions of the raw kalkwasser powder and additives were characterized by powder X-ray diffraction (PXRD) and energy-dispersive X-ray spectroscopy (EDX) (Fig. S1-S3). To evaluate the settlement enhancing ability of lime mortar substrates, the above substrates were compared to standard earthenware (EW) clay ceramics often used for coral restoration and fragmentation applications (unpigmented ceramic "frag" plugs, Boston Aqua Farms). ${ }^{17}$ The composition of the raw clay and the concentration of key elements in the final EW ceramic are reported in Supplementary Tables S1 and S2, respectively.

\section{Larval Settlement Experiments}

All substrates were conditioned in raw seawater in a flow-through aquarium system for 4 days immediately prior to settlement experiments. This short conditioning period was implemented to de-gas pores and remove any unreacted $\mathrm{Ca}(\mathrm{OH})_{2}$ from lime mortar substrates. It was not intended to grow mature, settlement-inducing microbial and algal communities, a process that takes weeks to months. ${ }^{56}$ After conditioning, the settlement substrates were placed in replicate $1 \mathrm{~L}$ polystyrene bins each containing $800 \mathrm{~mL}$ of FSW to evaluate specific larval settlement choices. For experiments with the full range of lime mortar additives, 1 substrate containing each additive or additive combination ( 7 substrates), a plain lime mortar substrate, and an earthenware ceramic reference tile were placed in each bin, for a total of 9 substrates per bin with 6 replicate bins. For glass fiber experiments, 2 substrates of each of the 3 glass fiber concentrations $(5 \%, 10 \%$, or $20 \%$ ) were placed in each bin, for a total of 6 substrates per bin. Multiple substrates were included per bin to keep the number of substrates per $\mathrm{mL}$ per added larvae more consistent with the 9-substrate experiment, while using the same total volume of FSW and number of larvae. Experimental bins were replicated three times for $A$. palmata and four times for $D$. labyrinthiformis. Settlement experiments were initiated by pipetting 200 larvae $( \pm 5 \%)$ into each bin. All larvae appeared healthy and were motile. Larval age was between 3-5 days old at the start of experiments. For both the 9-substrate and glass fiber experiments, larval settlement locations on both the top and bottom of each substrate were recorded after 7 days. At the end of the experiments, settled larvae were either outplanted, moved to aquaria for long-term monitoring, or sacrificed for microscopic analysis and substrate reuse. The methods for the preliminary settlement experiment can be found in the Supporting Information.

\section{Statistical Analysis}


The number of settlers on the top and bottom surfaces of each substrate was converted into the proportion of the total number of larvae added to each bin $(n=200)$ and normalized using an angular transformation (arcsine square root). The significance of settlement preferences was then assessed with a one-way analysis of variance (ANOVA) and post-hoc Tukey honestly significant difference (HSD) test in OriginPro and an in-house developed R script (DOI: 10.5281/zenodo.5140311). The total number of settlers (top + bottom) on each substrate type was used as the fixed variable. Because average larval settlement was only $20 \%$ in each bin, we assumed that larval settlement on one substrate did not affect the supply of larvae available to settle on any other substrates. All reported $p$ values from post-hoc Tukey HSD tests where the number of tests, $n$, was such that $0.05 n>1$, were false discovery rate (FDR) corrected ${ }^{57}$ with an FDR significance level of $\alpha=0.05$. To account for random effects related to substrate placement in each replicate bin, the location of each substrate was randomly assigned at the start of each experiment. All experimental bins were kept in a temperature-controlled laboratory matching the water temperature of the source reefs $\left(27.5 \pm 1.0^{\circ} \mathrm{C}\right)$.

\section{Substrate Characterization}

The final crystalline composition of substrates was determined by powder X-ray diffraction (PXRD) using a D8 Advance X-ray diffractometer (Bruker) equipped with a Cu source, TRIO optics, and a 2D Eiger2 R $500 \mathrm{~K}$ detector (Dectris). Carbonated lime mortar substrates were broken and ground into a fine powder with a mortar and pestle prior to analysis. PXRD data were quantified by Rietveld refinement using the open-source BGMN graphical user interface Profex. ${ }^{58}$ The surfaces of intact carbonated substrates were additionally analyzed by Raman spectroscopy (Raman 11, Nanophoton) using an excitation laser wavelength of $785 \mathrm{~nm}$ to confirm that the phases identified by PXRD were also present at the substrate surface (Fig. S4). The porosity and specific surface area (SSA, $\mathrm{m}^{2} \mathrm{~g}^{-1}$ ) of lime mortar substrates were determined from $\mathrm{N}_{2}$ gas sorption measurements conducted at $77 \mathrm{~K}$ (ASAP 200, Micrometrics). SSA was calculated using Brunauer-Emmett-Teller (BET) theory, and pore size distributions were extracted using a non-local density functional theory (NLDFT) model.

Additives and substrate surfaces were imaged by scanning electron microscopy (SEM, S-4700, Hitachi) combined with energy-dispersive X-ray spectroscopy (EDX, IXRF Systems) to determine the elemental composition of the raw additive powders. 3D surface maps of substrates were obtained by laser scanning confocal microscopy (VK-X1000, Keyence) using 20x and 50x objectives with a maximum z-resolution of $\sim 20 \mathrm{~nm}$. Surface area and quantitative roughness parameters including arithmetic mean roughness $\left(\mathrm{S}_{\mathrm{a}}\right)$, root mean square roughness $\left(S_{q}\right)$, and max height $\left(S_{z}\right)$ were extracted from the surface maps using MultiFile Analyzer software (Keyence) and averaged over 3 separate measurements. The exposed lengths and surface area of glass fibers was obtained by manual segmentation of the laser micrographs in ImageJ.

Due to the high porosity and absorbency of the lime mortar material, wettability could not be measured using the contact angle of water droplets on the dry material. Instead, surface wettability was determined by measuring the inverted contact angle of air bubbles on fully-saturated materials submerged in seawater using a goniometer system (Model 250, Ramé-Hart). Substrates were immersed face-down in artificial seawater (Instant Ocean Sea Salt) within a transparent quartz cell. Instant Ocean solutions were prepared in tap water at a concentration of $38 \mathrm{mg} \mathrm{mL}^{-1}$ to achieve a nominal seawater salinity of $35 \mathrm{ppt}$ (1.026 specific gravity) as determined with an optical refractometer (ATC, Agriculture Solutions; typical 
composition in Table S3). After substrates were immersed, an inverted syringe with a $180^{\circ}$ curved needle was used to deposit air bubbles (2-3 mm diameter) on the lower surface of the substrate (Fig. S5). For each substrate, measurements were obtained from three replicate air bubbles. Thirty automated measurements were recorded per bubble by taking the average value of the left and right contact angles. Differences in surface roughness, surface area, and wettability data were assessed with one-way ANOVA hypothesis testing as above. Pearson correlation coefficients were calculated in MATLAB (Mathworks) to investigate possible linear correlations between larval settlement rates and substrate surface area, mean roughness, or wettability.

The solubility of raw substrate materials and mineral additives in seawater was determined from chemical equilibrium modelling (Visual MINTEQ 3.1, KTH) to assess the potential of ion release during settlement experiments. The concentrations of major dissolved inorganic solids were derived from the standard seawater composition of Millero et al., ${ }^{59}$ using additional ion concentrations from Quinby-Hunt and Turehian ${ }^{60}$ (Supplementary Table S4). This general model was supplemented with $\mathrm{pH}, \mathrm{CO}_{3}{ }^{2-}, \mathrm{HCO}_{3}{ }^{-}$, and $\mathrm{pCO}_{2}$ measurement data from the reef at Piscaderabaai, Curaçao, which was the source of FSW used in larval settlement experiments. Ion release from selected substrates was measured by inductively coupled plasma optical emission spectrometry (ICP-OES, Optima 8300, PerkinElmer) with an uncertainty of $<0.05$ ppm for all elements analyzed. Substrates were immersed in $200 \mathrm{~mL}$ of artificial seawater in food-grade polyethylene terephthalate (PETE) plastic containers, and $2 \mathrm{~mL}$ water samples were taken at specified times over 28 days of soaking to monitor release ( $n=3$ replicates).

\section{Results and Discussion}

\section{Coral Larvae Exhibit a Preference for Lime Mortar Substrates}

In search of a more effective larval settlement substrate, we first conducted a preliminary trial of substrates with different shapes, additives, and base materials (Fig. 2a). D. labyrinthiformis larvae were presented with substrates fabricated from lime mortar, calcium phosphate (CaP), acrylic, and polydimethylsiloxane (PDMS) in a randomized settlement choice experiment. Substrates made from these materials were modified through surface molding and the inclusion of additives including sands and glasses (Fig. S6 and Table S5, additives discussed below). Strikingly, regardless of the additive composition or surface topography, $D$. labyrinthiformis larvae only settled on substrates made with lime mortar as the base material (Fig. 2a); no settlers were observed on any substrates made from CaP, acrylic, or PDMS. Therefore, lime mortar was selected as the base material for further characterization, optimization, and larval experiments. 

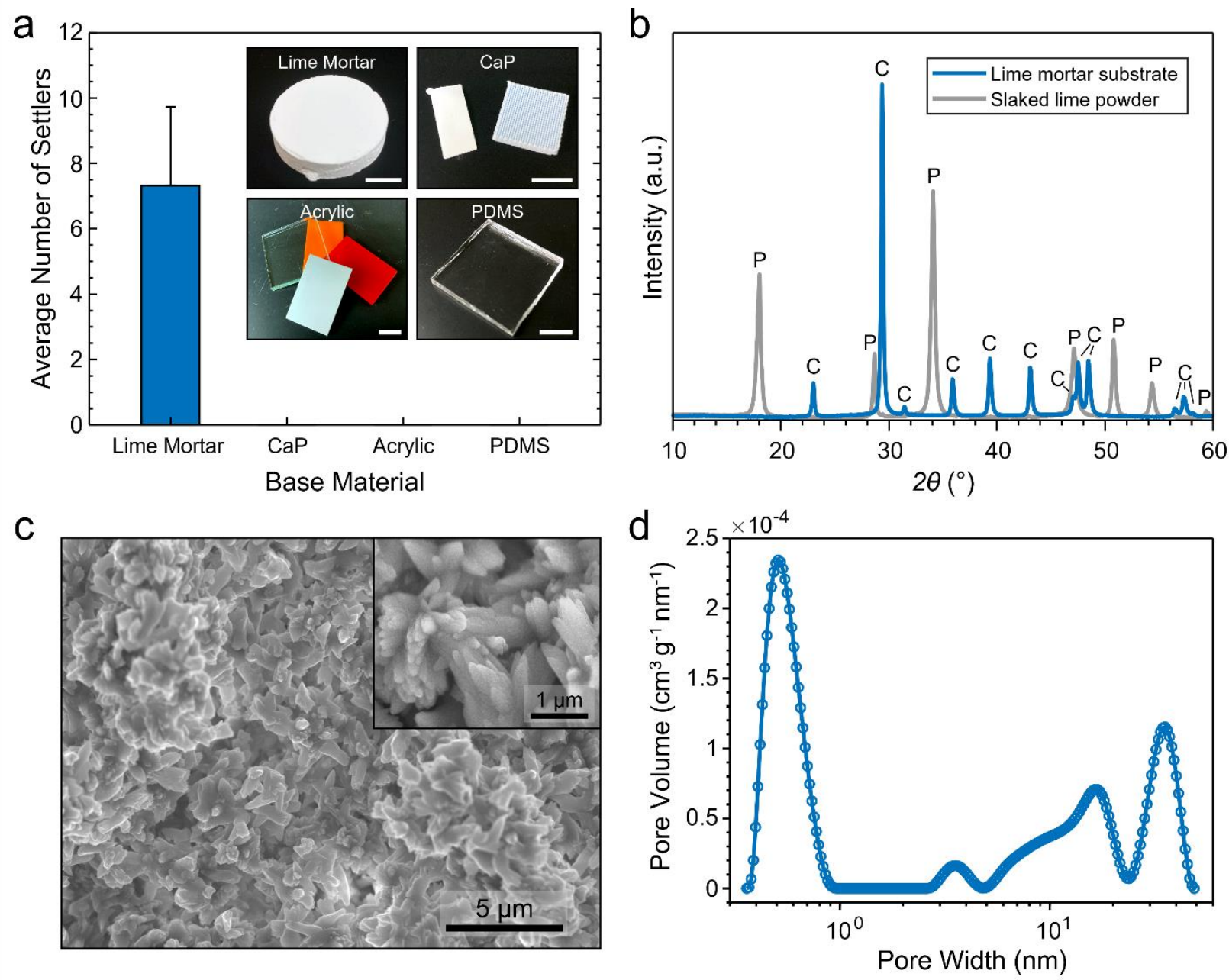

Figure 2. Production, selection, and characterization of lime mortar as a substrate material for coral larval settlement. (a) Settlement of $D$. labyrinthiformis larvae in choice experiments with engineered substrates made from four base materials: lime mortar, calcium phosphate (CaP), acrylic, and polydimethylsiloxane (PDMS). Larvae showed a strong preference for lime mortar substrates relative to the three other material types. Error bars represent the standard error of the mean ( $n=4$ replicate bins, $n=200$ larvae per bin). Material types were replicated within the bins to present a variety of colors/textures, but these features had no observable effect on larval settlement for the non-preferred base materials. Thus, data were pooled by material class (see Table S5 in the Supporting Information for a full list of substrates). The insets show an example photo of each of the substrate types (scale bars are $1 \mathrm{~cm}$ ). (b) X-ray diffraction patterns of raw kalkwasser powder and lime mortar substrates showing full conversion of portlandite $(P)$ to calcite $(C)$ crystals over the seven days of accelerated carbonation. (c) Scanning electron micrographs of the top surface of a carbonated lime mortar substrate, revealing an interconnected network of scalenohedral calcite crystals of several microns in length. (d) Non-local density functional theory (NLDFT) model of the pore size distribution of carbonated lime mortar substrates obtained from gas sorption measurements.

\section{$\mathrm{CO}_{2}$ Accelerates Lime Mortar Carbonation}

Lime mortar is typically prepared by mixing hydrated lime powder $\left(\mathrm{Ca}(\mathrm{OH})_{2}\right.$, portlandite) with water and allowing the paste to carbonate in air. However, this process is slow (months to years), and incomplete 
carbonation leaves unreacted $\mathrm{Ca}(\mathrm{OH})_{2}$ within substrates, which can compromise the integrity of the material and produce low $\mathrm{pH}$ conditions that could be harmful to corals. Therefore, the carbonation of lime mortar substrates was accelerated in a high $\mathrm{CO}_{2}$ environment. PXRD confirmed that $>99 \%$ conversion of $\mathrm{Ca}(\mathrm{OH})_{2}$ into $\mathrm{CaCO}_{3}$ could be achieved within 7 days using this method (Fig. $2 \mathrm{~b}$ and $\mathrm{S} 7$ ). The carbonated mortars had a composition of $99.4 \pm 0.26 \%$ calcite, $0.26 \pm 0.28 \%$ portlandite, and $0.29 \pm 0.04 \%$ quartz (mean \pm standard deviation, $n=3$ ). Microscopic analyses of the carbonated substrates revealed a dense network of interconnected scalenohedral calcite crystals of $\sim 1-3 \mu \mathrm{m}$ in size, punctuated by similarly sized gaps and pores (Fig. 2c). In addition to these macropores (>50 nm), complementary gas sorption measurements showed that the substrates also had a range of micro- $(<2 \mathrm{~nm})$ and meso-pores (2-50 nm; Fig. 2d), which were especially concentrated around $0.5 \mathrm{~nm}$ and $35 \mathrm{~nm}$ in width, respectively. Analysis of gas sorption data also provided a Brunauer-Emmett-Teller (BET) specific surface area of $8.29 \mathrm{~m}^{2} \mathrm{~g}^{-1}$.

\section{Additives Modify Lime Mortar Properties}

To investigate the settlement preferences of coral larvae in response to diverse inorganic cues, we modified the base lime mortar material with two additives from each of three material groups: (1) natural sands, (2) synthetic glasses, and (3) alkaline earth carbonates (Fig. 3). Natural sands are traditionally used as the "aggregate" that adds strength to mortars and cements. ${ }^{61}$ From this category, we selected a standard, quartz-rich sand and a high-aragonite sand. The selection of two different types of sand enabled the comparison of larval preference for an abundant non-Ca-based mineral (here, silica/quartz) and the mineral found in abundance on reefs in both the skeletons of living corals and the reef structure that they leave behind (i.e., aragonite). From glasses, we selected borosilicate glass fibers and a bioactive glass powder. Glass fibers are a standard insoluble material added to increase the strength of composite resins, and bioactive glasses are partially soluble silicates that release $\mathrm{Ca}^{2+}$ and $\mathrm{PO}_{4}{ }^{3-}$ ions and aid in bone growth ${ }^{62}$ and $\mathrm{CaCO}_{3}$ mineralization. ${ }^{63}$ Finally, we also selected two alkaline earth carbonate additives: strontianite $\left(\mathrm{SrCO}_{3}\right)$ and dolomite $\left(\mathrm{CaMg}\left(\mathrm{CO}_{3}\right)_{2}\right)$. Strontium and magnesium are known to be essential for maintaining coral health in aquarium systems due to their role in coral mineralization. ${ }^{13,64-65}$ We hypothesized that the presence of these elements in substrates could influence larval settlement and might even aid in the initial mineralization and survival of settled polyps.

We investigated the effect of these additives on both mortar carbonation and the final structure of the substrates after carbonation was complete. None of the additives strongly inhibited carbonation (>98\% conversion for all additives). However, most additives did affect the final polymorphism of the mortar. In addition to calcite, the presence of aragonite was detected in substrates containing quartz sand ( $1 \mathrm{wt} \%$ aragonite), glass fibers (1.5 wt\%), bioactive glass (0.9 wt\%), strontianite (22.7 wt\%), and in substrates containing the combination of dolomite and strontianite (6.4 wt\%; Fig. S7). Additionally, substrates containing aragonite sand had $\sim 2.5 \mathrm{wt} \%$ more aragonite than expected based on the amount of sand added; the final substrates had $7.7 \mathrm{wt} \%$ aragonite in total, whereas only $5.1 \mathrm{wt} \%$ was added initially (when taking into account the purity of the aragonite sand and the substrate mass gain due to carbonation). With the exception of the aragonite sand additive, PXRD of the raw additive powders confirmed that the aragonite was produced solely as a result of carbonation and not due to aragonitic impurities in the powders (Fig. S3). The particularly large amount of aragonite formed in the presence of strontianite is attributed to the documented stabilization of aragonite by $\mathrm{Sr}^{2+}$ ions. ${ }^{66}$ The only additive that did not appear to result in some aragonite formation during carbonation was dolomite when used as the sole 
additive. Despite these differences in both the added and resultant compositions of the mortars, the final pore size distribution and specific surface area of substrates containing different additives were similar (Fig. S8 and Table S6).
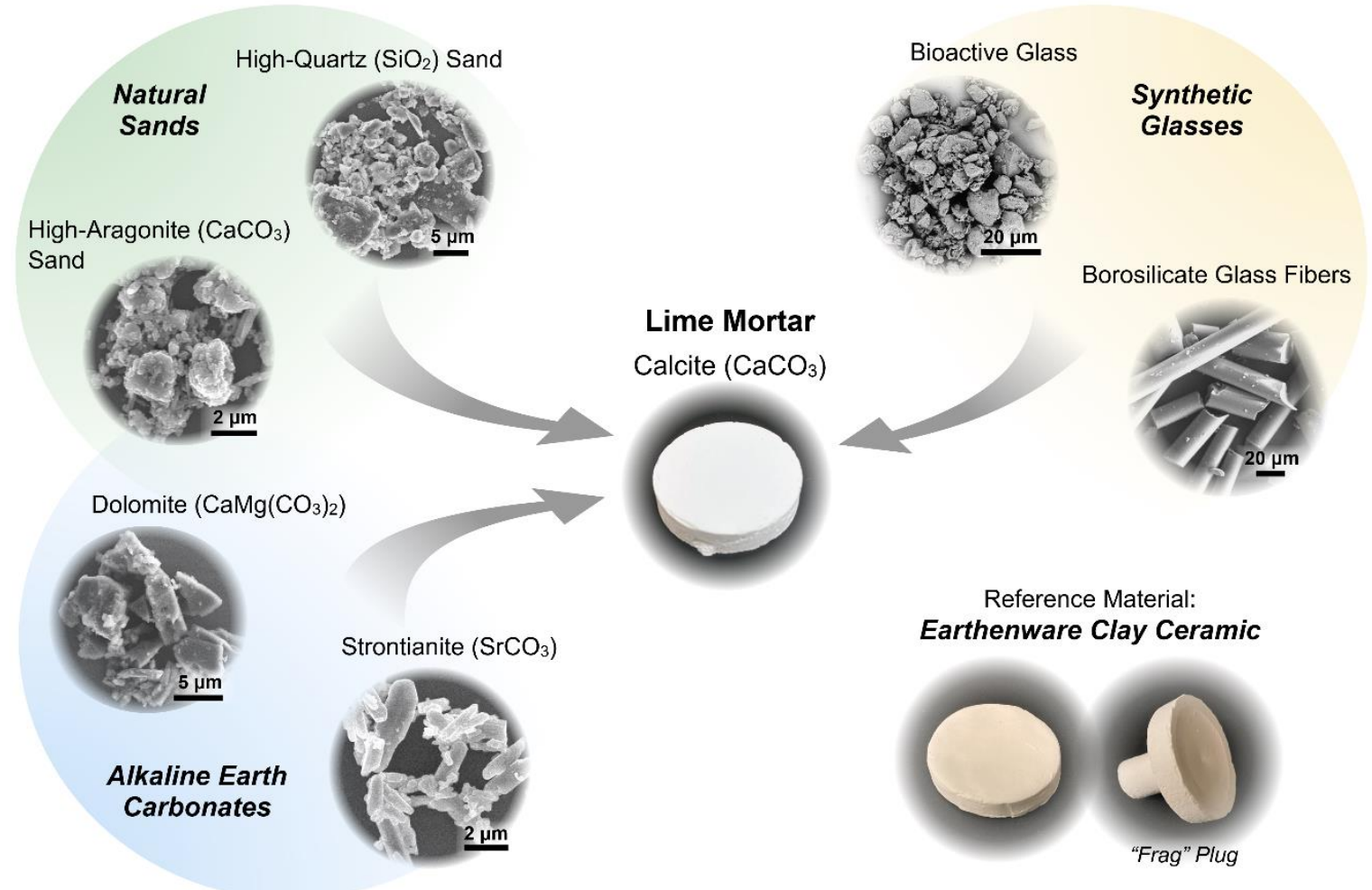

Figure 3. Illustration of the additives selected for incorporation into lime mortar substrates to investigate coral larval settlement preferences. The additives can be grouped into three categories: natural sands, synthetic glasses, and alkaline earth carbonate minerals. The plain lime mortar substrates and substrates containing additives were also compared to substrates made from a standard earthenware clay ceramic material. This type of ceramic is commonly used in coral research and propagation to make fragmentation or "frag" plugs (right image). Here, ceramic disks were used without the addition of a stem (left image).

\section{Coral Larvae Settle onto Substrates with Lower Glass Fiber Content}

When A. palmata and D. labyrinthiformis larvae were presented with a choice between lime mortar substrates containing three different concentrations of glass fibers $(5,10$, and $20 \mathrm{wt} \%)$, both species displayed a settlement preference for substrates with lower glass fiber content (Fig. 4a), and no larvae of either species settled on the substrates containing $20 \mathrm{wt} \%$ glass fibers. Settlement of A. palmata on $5 \mathrm{wt} \%$ and $10 \mathrm{wt} \%$ substrates was higher than on $20 \mathrm{wt} \%$ substrates ( $p=0.002$ and $p=0.012$, respectively). Settlement of $D$. labyrinthiformis on 5 wt\% substrates was higher than on both 10 wt\% $\left(p=4.83 \times 10^{-5}\right)$ and $20 \mathrm{wt} \%\left(p=1.11 \times 10^{-6}\right)$ substrates, and settlement on $10 \mathrm{wt} \%$ substrates was higher than on $20 \mathrm{wt} \%$ substrates $(p=0.003)$. 
a

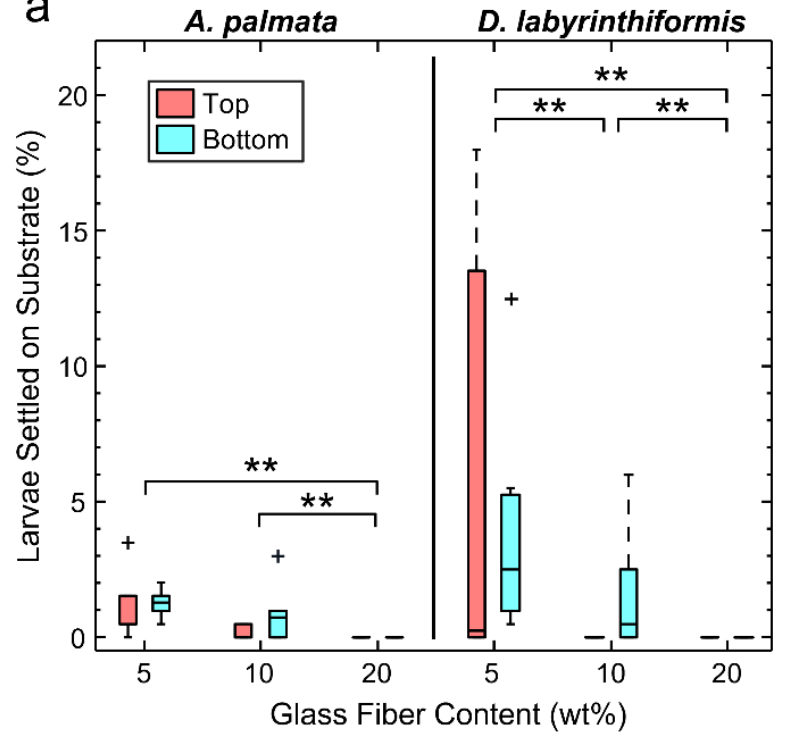

b

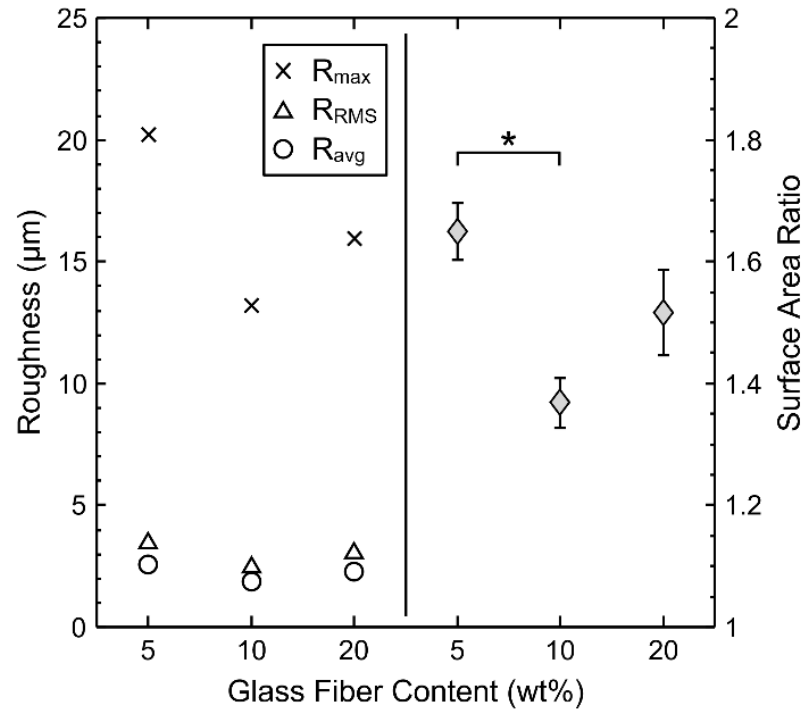

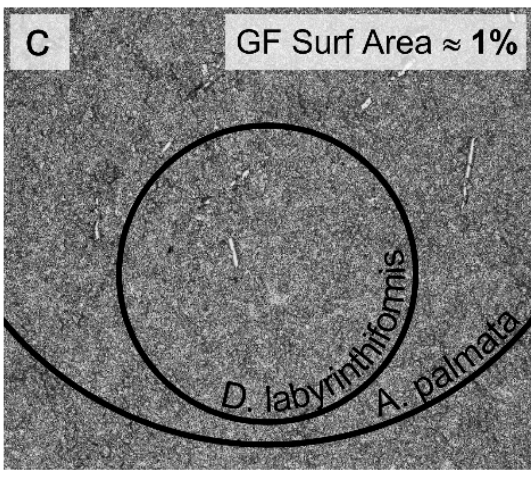

$5 w t \%$

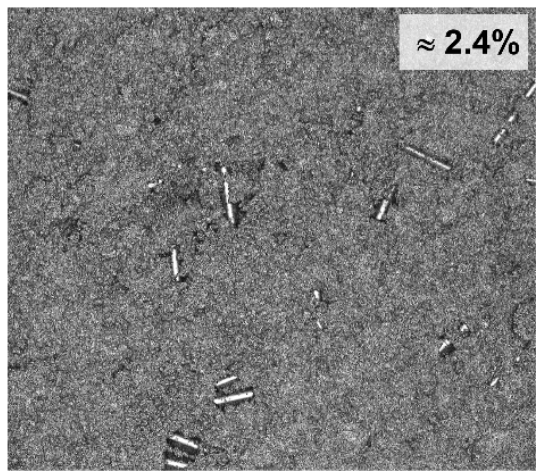

$10 \mathrm{wt} \%$

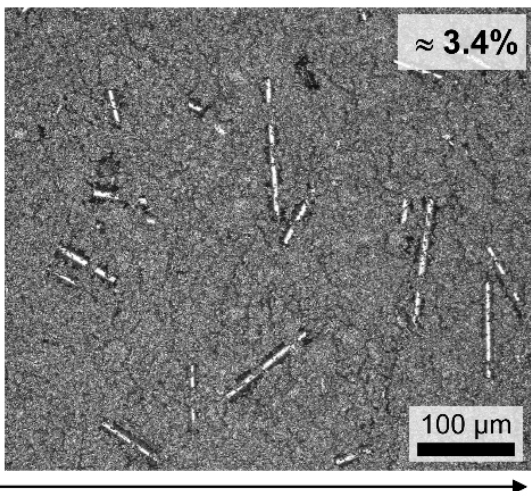

$20 w t \%$

Figure 4. Coral larvae exhibit a substrate preference in response to the glass fiber content of lime mortar. (a) Results from settlement choice experiments with lime mortar substrates containing $5 \%, 10 \%$, or $20 \%$ glass fibers by dry weight. The results are presented as the percent of the initial cohort of larvae added to each bin $(n=200)$ that settled on the top or bottom of a substrate. In box-and-whisker plots, the black lines display the median value, boxes encompass the inner quartile range (IQR, between upper and lower quartiles), whiskers denote data within $1.5 \times$ IQR, and the crosses represent individual data points outside this range. Significant differences in the proportion of total settlement (i.e., settlement on the top and bottom of the substrate) between substrate types are denoted by asterisks (*: $p<0.05 ;{ }^{*}: p<0.01$; post-hoc Tukey HSD). (b) Quantification of surface roughness and surface area of substrates containing glass fibers by 3D laser scanning profilometry. Roughness results are reported as the arithmetic mean roughness ( $R_{\text {avg }}$ ), root mean square (RMS) roughness ( $\left.R_{R M S}\right)$, and maximum peak height ( $\left.R_{\max }\right)$. Surface area is presented as the surface area ratio, i.e., the total surface area divided by the planar measurement area (20x fieldof-view $\approx 0.367 \mathrm{~mm}^{2}$ ). Error bars denote the standard error of the mean. (c) Representative laser scanning confocal micrographs of lime mortar substrates revealing the differences in the percent of substrate surface area occupied by glass fibers (GF Surf Area) based on concentration. For comparison of substrate characteristics to coral size, the large and small arcs overlaid on the $5 \mathrm{wt} \%$ image represent the average diameter of $A$. palmata and $D$. labyrinthiformis larvae, respectively. The scale bar is $100 \mu \mathrm{m}$ and applies to all three panels. 
In the absence of any chemical differences between the three substrate types in either the base material or additives, we might expect that differences in surface topography due to differences in glass fiber content would be the main factor influencing larval settlement behavior. For marine larvae in general, rougher surfaces with a greater number of points for larval attachment are recognized as promoting settlement. ${ }^{40}$ However, all three substrates tested here were smooth, and the inclusion of the glass fibers (16 $\mu \mathrm{m}$ average diameter, $32.5 \mu \mathrm{m}$ average exposed fiber length on substrate surface; Fig. S9) did not modify roughness on the length scales typically considered by Attachment Point Theory, i.e., close to the larval size. For reference, the average size of $A$. palmata larvae is $\approx 700 \mu \mathrm{m}$ and that of $D$. labyrinthiformis

is $\approx 300 \mu \mathrm{m} .{ }^{27,67}$ This qualitative description was confirmed by $3 \mathrm{D}$ surface analysis of the substrates, which revealed no large differences in mean roughness as a function of glass fiber content (Fig. 4b). This analysis also provided the relative surface area available for larval contact on each substrate type, presented as the surface area ratio, or the factor by which the surface area is increased from a perfectly flat plane (Fig. $4 b)$. While there was a significant difference in the surface area ratio of substrates containing $5 \mathrm{wt} \%$ and 10 wt\% glass fibers $(p=0.024)$, we found no significant correlations between larval settlement and mean roughness or surface area ratio for either species (Fig. S10). Therefore, the observed preference for substrates with lower glass fiber content suggests that larvae may be able to sense individual glass fibers or groupings of fibers, neither of which strongly influenced these average surface metrics.

As would be expected, we observed that the number of exposed glass fibers at the substrate surface increased with glass fiber concentration (Fig. 4c). Although the absolute change in the surface area coverage of glass fibers was small, it would not have been possible for larvae of either species to settle on the 20 wt\% glass fiber substrates without contacting multiple fibers, based on the distribution of the fibers and the size of the larvae (Fig. 4c). If the fiber ends felt sharp to the larvae, or if fiber smoothness, curvature, or another property in some way inhibited larval attachment, then it is conceivable that the larvae might have chosen to avoid the fibers. Indeed, analysis of the substrate surfaces did reveal a strong negative correlation between $A$. palmata settlement and the surface area occupied by exposed glass fibers ( $r=-0.999, p=0.032$; Fig. S11). There was also a negative correlation between exposed glass fiber surface area and $D$. labyrinthiformis settlement, although this was not statistically significant $(r=-0.96, p$ $=0.182$ ).

Our results then indicate that larvae are sensitive to substrate heterogeneities with characteristic length scales of more than an order of magnitude smaller than their size - here, dispersed $16 \mu \mathrm{m}$ diameter glass fibers. As most previous, controlled laboratory studies of Attachment Point Theory have utilized homogenous substrate materials such as micropatterned PDMS, ${ }^{39-40}$ these results warrant further investigation and a possible extension of Attachment Point Theory to consider heterogenous substrates and composite materials. Our results also suggest that future materials studies should test a range of additive concentrations as these can have a large effect on larval settlement preference.

\section{Coral Larvae Settle onto Substrates containing Quartz Sand or Strontianite}

Next, we examined settlement preferences in relation to material composition by presenting larvae with a choice between lime mortar substrates containing six different inorganic additives (Fig. 3), a combination of additives (dolomite and strontianite), and control substrates. A. palmata larvae exhibited a slight preference for substrates containing quartz sand $(p<0.05$ compared to bioactive glass, dolomite, 
strontianite, and earthenware ceramic; Fig. 5a), and D. labyrinthiformis larvae exhibited a strong preference for substrates containing quartz sand or strontianite $(p<0.001$ compared to all other treatments; Fig. 5b). Notably, the earthenware ceramic substrates-commonly used in larval settlement and coral propagation as "frag plugs" and included here as a reference material-had some of the lowest settlement rates for both species. We also observed that $A$. palmata larvae preferred to settle on the bottoms of substrates while $D$. labyrinthiformis larvae preferred the substrate tops (Fig. 5).
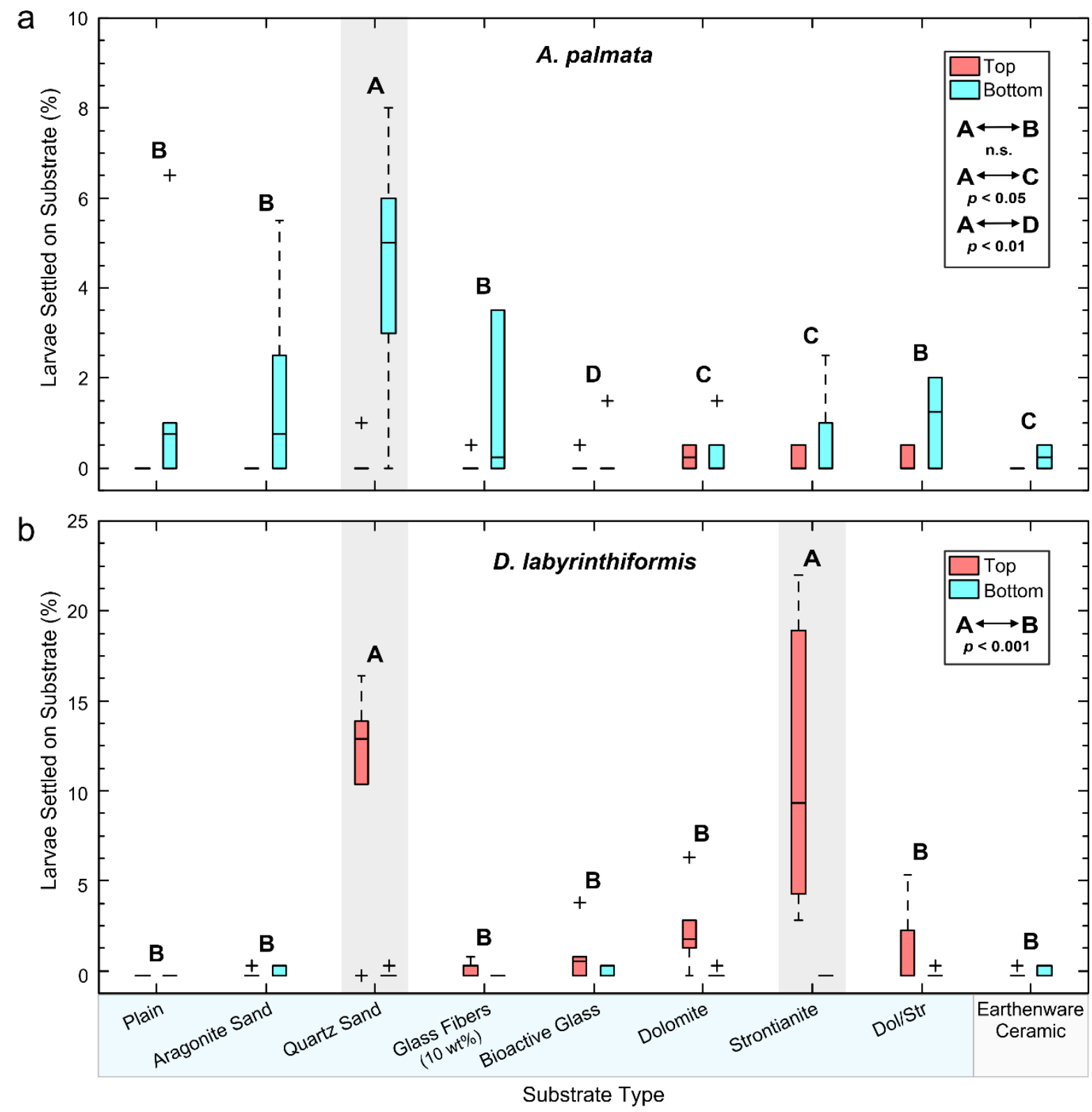

Figure 5. Results from settlement choice experiments using coral larvae of two species and lime mortar substrates with a variety of additives. (a) A. palmata and (b) D. labyrinthiformis larvae were presented with lime mortar-based substrates containing the indicated additives ( $n=6$ replicates per experiment, choice of 9 substrates per replicate). A substrate made from lime mortar without an additive (Plain) and a common earthenware ceramic substrate (Earthenware) were used as internal references. Results are presented as the percent of larvae that settled on the 
top or bottom of a substrate ( $n=200$ larvae per bin). Data are presented as box-and-whisker plots: black lines denote the median value, boxes encompass the inner quartile range (IQR, between upper and lower quartiles), whiskers denote data within $1.5 \times \mathrm{IQR}$, and the crosses denote individual data points outside this range. Significant differences in the proportion of total settlement (i.e., settlement to either the top or bottom) between substrate types are denoted by letters above each substrate type (self-defined groups A, B, C, and D based on post-hoc Tukey HSD tests). There were no significant differences between groups $B, C$, and $D$ (n.s.).

Like the glass fiber experiment, subsequent surface analysis of the substrates did not reveal major topographical differences that could explain the observed settlement preferences (Fig. 6a). There were no significant differences in the mean roughness of any of the lime mortar-based substrates, which were all smoother than the earthenware ceramic substrates ( $p<0.01$; Fig. $6 \mathrm{~b})$. Additionally, quartz sand and earthenware ceramic substrates had greater surface area ratio than all substrates except for plain lime mortar ( $p<0.05$; Fig. $6 \mathrm{~b}$ ), yet as in the glass fiber experiment, these differences were not correlated with larval settlement (Fig. S12).

Further, we performed inverted contact angle analysis to determine if changes in surface wettability caused by the additives could explain the observed differences in substrate preference (Fig. 7, insets). According to Cassie's Law, for a chemically heterogenous surface with two components, the effective contact angle of a droplet $\left(\theta_{c}\right)$ is related to the inherent contact angles of both components and the fraction of the surface that they each occupy. ${ }^{68}$ For the lime mortar substrates containing additives, this relationship can be described by the equation:

$$
\cos \theta_{c}=\alpha_{l} \cos \theta_{l}+\alpha_{a} \cos \theta_{a}
$$

where $\alpha_{l}$ and $\alpha_{a}$ are the surface area fraction and $\theta_{l}$ and $\theta_{a}$ are the inherent contact angle of the lime mortar base and additive materials, respectively. Assuming the small differences in surface roughness (Fig. 6b) did not contribute significantly to the measured contact angle, these measurements therefore provide direct insight into the contribution of the inherent additive wettability (i.e., $\theta_{a}$ ) to the overall wettability of the substrate. Indeed, lime mortar-based substrates displayed reproducible and significantly different wettability values depending on the additive $(p<0.001$; Fig. 7$)$. Compared to the known hydrophobic material PDMS, all lime mortar substrates were hydrophilic, presenting average air contact angles between $150^{\circ}$ and $170^{\circ}$ (with the theoretical maximum being $180^{\circ}$ ). However, we found no correlation between these differences in wettability and the larval settlement preferences observed for either coral species (Fig. S13). 
a

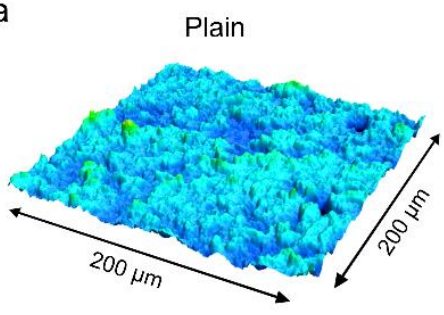

Glass Fibers (10 wt\%)

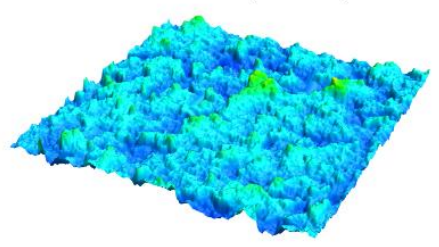

Strontianite

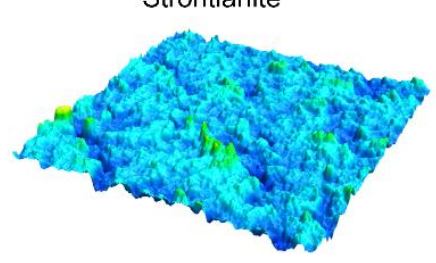

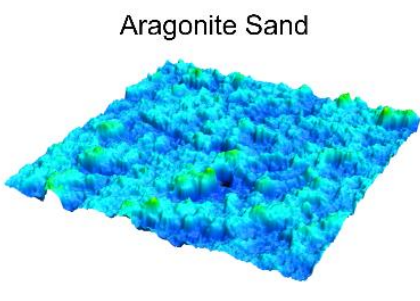

Bioactive Glass

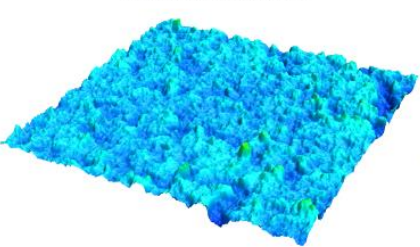

$\mathrm{Dol} / \mathrm{Str}$

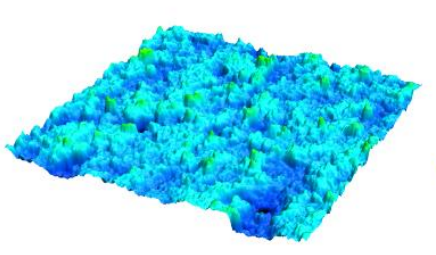

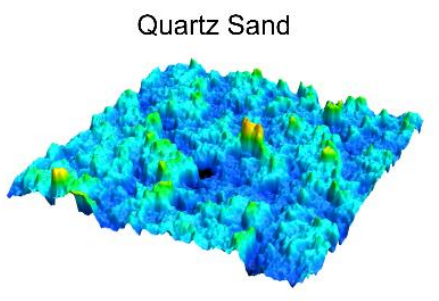

Dolomite

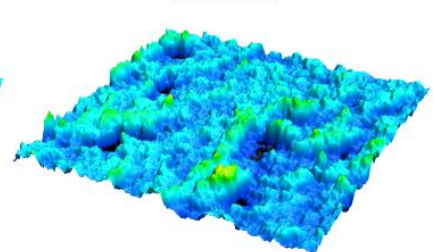

Earthenware Ceramic

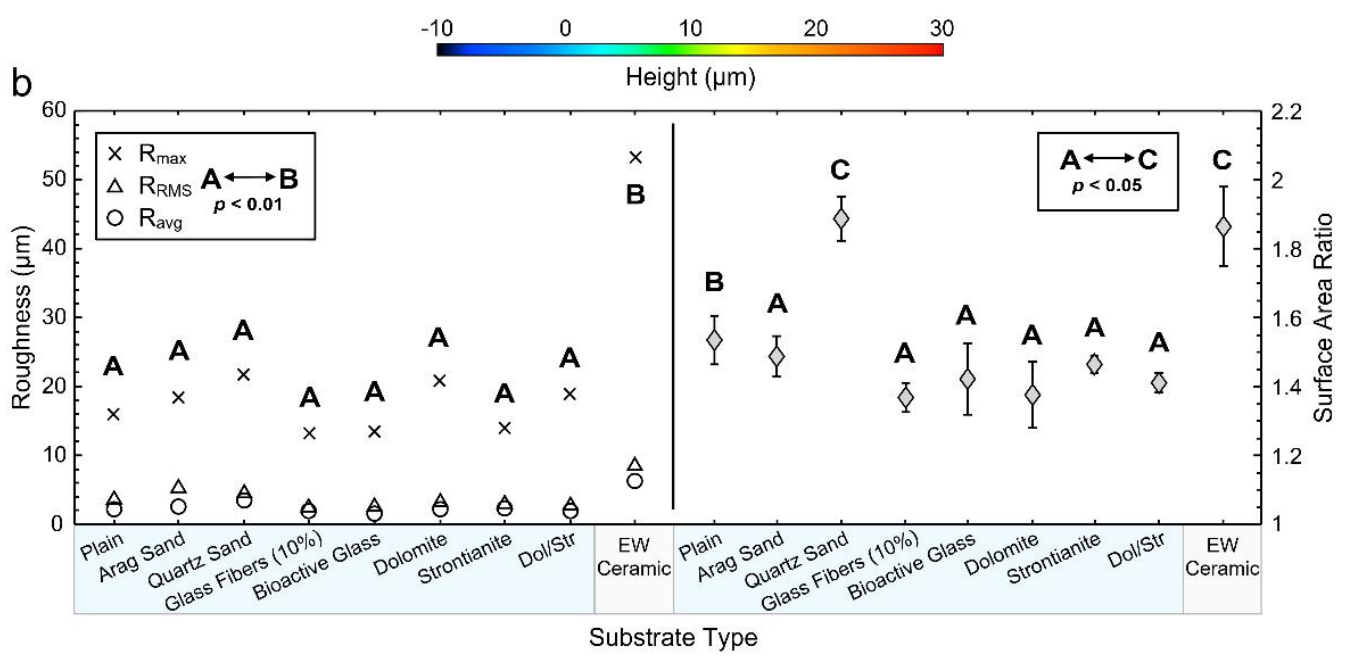

Figure 6. Topographical characterization of lime mortar and earthenware (EW) ceramic substrates used in larval settlement choice experiments. (a) Representative 3D laser confocal surface maps of settlement substrates obtained using a 50x objective for visualization of finer details. (b) Quantitative analysis of 3D surface maps obtained using a 20x objective for a larger field-of-view. Roughness is reported as the arithmetic mean roughness (Ravg), root mean square (RMS) roughness ( $\left.R_{R M S}\right)$, and maximum peak height $\left(R_{\max }\right)$. There were no significant differences in mean roughness between lime mortar-based substrates, but the EW ceramic substrate was significantly rougher than all lime mortar substrates ( $p<0.01$, self-defined groups A and B; post-hoc Tukey HSD). Surface area is presented as the surface area ratio, i.e., the total surface area divided by the planar measurement area $(20 x$ field-of-view $\approx 0.367$ $\mathrm{mm}^{2}$ ). Error bars denote the standard error of the mean. Significant differences in the surface area ratio between substrate types are denoted by letters above/below each substrate type (self-defined groups A, B, and C; post-hoc Tukey HSD). There were no significant differences between groups A and B or B and C. 


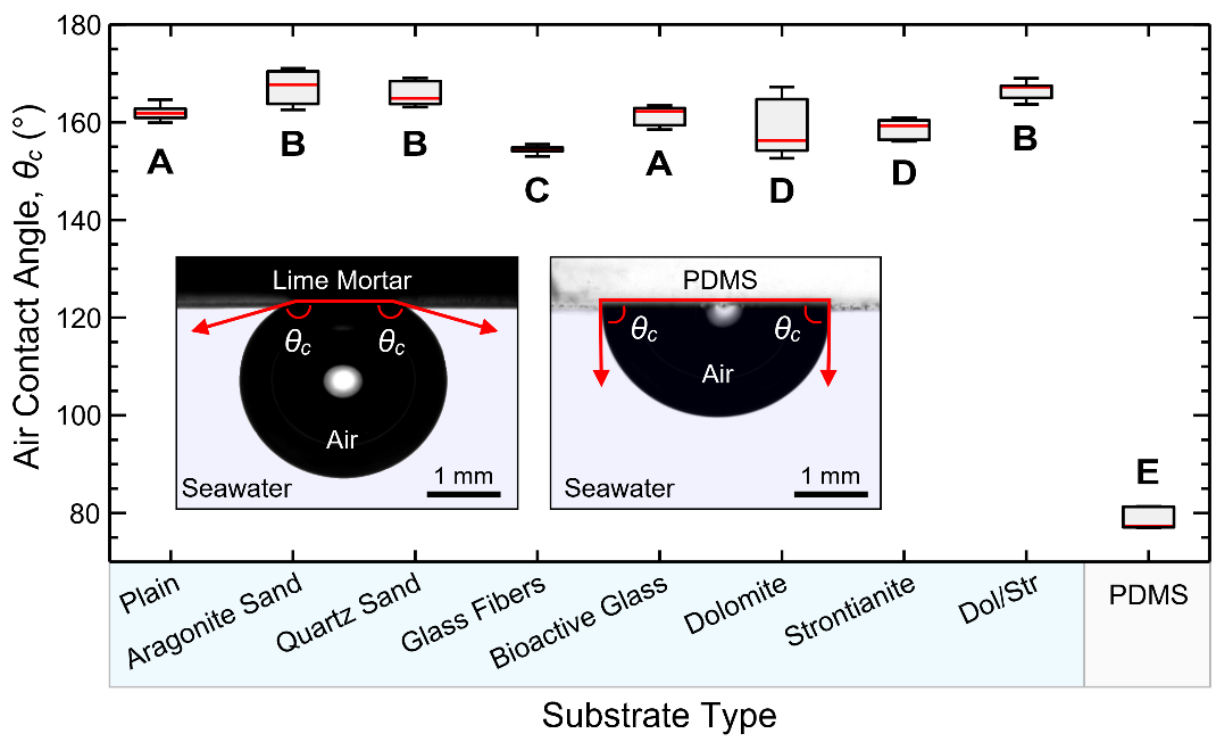

Figure 7. Measurement of the wettability of lime mortar substrates by air contact angle. Higher air contact angles $\left(\theta_{c}\right)$ correspond to greater hydrophilicity (i.e., wettability). Lime mortar substrates were compared to a known hydrophobic material, PDMS, to confirm that inverted measurements (air-in-seawater) can capture changes in wettability. In the box-and-whisker plots, the red lines display the median value, boxes encompass the inner quartile range (IQR, between upper and lower quartiles), and whiskers represent data within $1.5 \times$ IQR. Significant differences in wettability between substrate types are denoted by letters below each box plot (self-defined groups A, B, C, D, and $E$ are statistically distinct from each other; $p<0.001$; post-hoc Tukey HSD). The insets display representative micrographs that illustrate the inverted experimental setup and the difference in contact angle between lime mortar substrates and PDMS.

\section{Soluble Additives Are Released in Seawater}

After excluding differences in average surface topography and wettability as factors that could be responsible for the observed differences in larval substrate preference, we turned our attention to the possibility that larvae were chemically attracted to the specific additives in the materials themselves: $A$. palmata to quartz sand and $D$. labyrinthiformis to quartz sand and strontianite. A chemical equilibrium model was developed to simulate the solubility of the substrate additives in seawater and to identify the undersaturated additives that would produce a net release of ions into the water column that could be sensed by larvae. While most of the mineral additives were supersaturated in seawater (and therefore resulted in a net uptake of ions by the material), amorphous silica $\left(\mathrm{SiO}_{2}\right)$ and strontianite were both undersaturated (Fig. 8a). Although crystalline quartz $\left(\mathrm{SiO}_{2}\right)$ was saturated, the highly basic lime mortar carbonation process $(\mathrm{pH} \approx 12)$ solubilized some of the quartz sand ${ }^{69}$ as confirmed by ICP-OES. Therefore, both of the preferred substrate types contained soluble compounds that could have diffused into the surrounding seawater during the larval settlement experiments. Because the thermodynamic solubility products $\left(\mathrm{K}_{\mathrm{sp}}\right)$ for bioactive and borosilicate glass required for solubility modeling are not available, we estimated their potential $\mathrm{Ca}$ and Si release, respectively, from the literature. ${ }^{62,70}$ In high salt solutions, bioactive glass is approximately 4 orders of magnitude more soluble than borosilicate glass (Fig. 8a). 


\begin{tabular}{|c|c|c|}
\hline & Material & Saturation Index $(S I)$ \\
\hline & Portlandite $\left(\mathrm{Ca}(\mathrm{OH})_{2}\right)$ & $-8.825(-9.083)$ \\
\hline & Calcite $\left(\mathrm{CaCO}_{3}\right)$ & $0.751(0.405)$ \\
\hline 으 & Aragonite $\left(\mathrm{CaCO}_{3}\right)$ & $0.608(0.263)$ \\
\hline$\frac{\pi}{3}$ & Dolomite $\left(\mathrm{CaMg}\left(\mathrm{CO}_{3}\right)_{2}\right)$ & $2.323(1.632)$ \\
\hline$\frac{E}{n}$ & Strontianite $\left(\mathrm{SrCO}_{3}\right)$ & $-0.476(-0.821)$ \\
\hline & Quartz $\left(\mathrm{SiO}_{2}\right)$ & $0.081(0.085)$ \\
\hline & Silica $\left(\mathrm{SiO}_{2}\right)$ & $-1.2(-1.195)$ \\
\hline \multirow{2}{*}{ ني. } & Bioactive glass & $10^{0}\left(\mathrm{mg} \mathrm{Ca} \mathrm{m}^{-2} \mathrm{~h}^{-1}\right)$ [ref. 62] \\
\hline & Borosilicate glass & $10^{-4}\left(\mathrm{mg} \mathrm{Si} \mathrm{m}^{-2} \mathrm{~h}^{-1}\right)$ [ref. 70$]$ \\
\hline
\end{tabular}

b

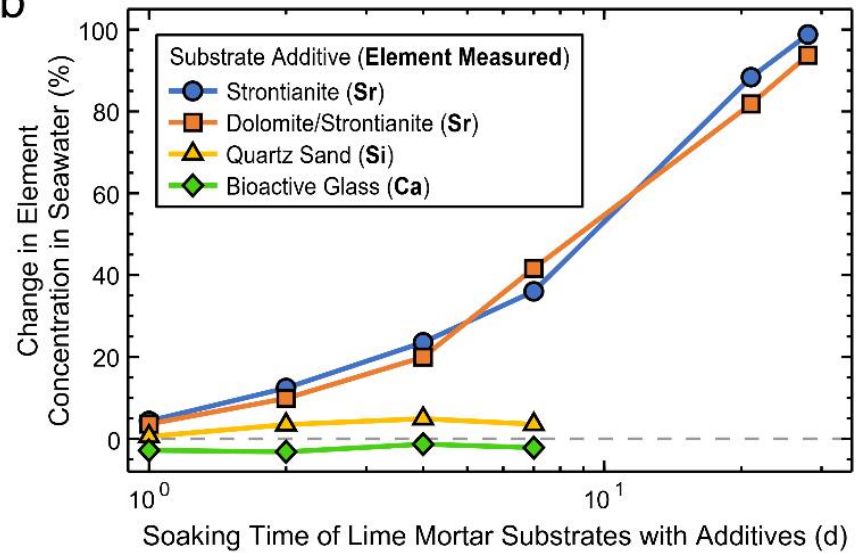

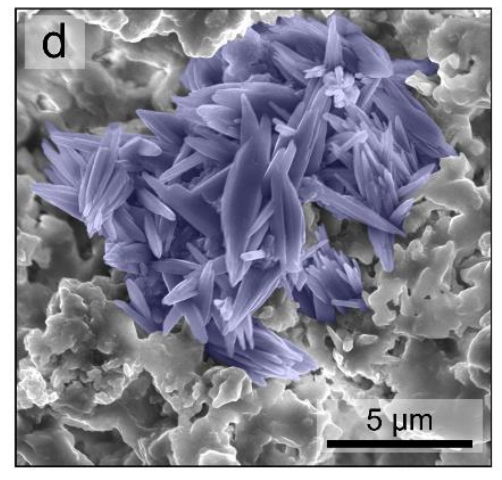

Figure 8. Release of soluble additives from lime mortar substrates. (a) Mineral solubility table from seawater chemical equilibrium simulations using input data from Piscaderabaai, Curaçao. The saturation indices of undersaturated minerals are red. The values in parentheses were simulated using standard seawater conditions. Kinetic release rates of $\mathrm{Ca}$ and $\mathrm{Si}$ from bioactive glass and borosilicate glass fibers, respectively, from literature are included in units of mass released per material surface area per time. (b) Release of the indicated elements during substrate soaking experiments obtained by inductively coupled plasma-optical emission spectrometry (ICP-OES). The results are reported as the percent change in the concentration of the indicated element during larval settlement experiments assuming uniform mixing. Error bars of the uncertainty in concentration of the element measured by ICP-OES are smaller than the data markers. (c-e) SEM micrographs of lime mortar substrates. (c) Lime mortar with quartz sand, demonstrating the general morphology of the mortar network. (d) Lime mortar with strontianite, illustrating needle-like aragonitic deposits (false-colored blue). (e) Lime mortar with dolomite/strontianite, illustrating large deposits of rhombohedral dolomite crystals (false-colored red).

Lime mortar substrates containing soluble additives (quartz sand, strontianite, dolomite/strontianite, and bioactive glass) were placed in artificial seawater to experimentally determine the release profiles of key ions over time (Fig. 8b). The bioactive glass substrates showed a net uptake of $\mathrm{Ca}^{2+}$ ions from the artificial seawater, likely due to competition between the release of $\mathrm{Ca}^{2+}$ from bioactive glass particles and the sequestration of $\mathrm{Ca}^{2+}$ by the overgrowth of supersaturated calcite crystals in the mortar. This competition suggests that lime mortar substrates may not be ideal for applications in which the release of $\mathrm{Ca}^{2+}$ ions is desired. The quartz sand substrates released approximately $0.11 \%$ of their Si content $(0.27 \mathrm{mg})$ over the first 4 days of soaking (likely as $\mathrm{SiO}(\mathrm{OH})_{3}{ }^{-}$ions). Assuming similar release characteristics during larval settlement experiments, this would have resulted in a $5 \%$ increase in Si concentration in the settlement 
bins. No additional net Si release was observed, which we attribute to competition between Si release and quartz growth. Based on ICP-OES measurements of solubilized quartz sand, we estimate up to $60 \%$ of soluble silica remained after 4 days. The strontianite substrates released approximately $2.4 \%$ of their $\mathrm{Sr}$ content $\left(6 \mathrm{mg}\right.$ ) over the first 7 days of soaking, increasing the concentration of $\mathrm{Sr}^{2+}$ in settlement bins by $36 \%$ (Fig. 8b). Continued monitoring of the substrates over 28 days of soaking showed that the $\mathrm{Sr}^{2+}$ release followed a resource-limited exponential profile that resulted in a doubling of the initial $\mathrm{Sr}^{2+}$ concentration. Surprisingly, even though they contained only half the amount of strontianite, the substrates containing both dolomite and strontianite had remarkably similar $\mathrm{Sr}^{2+}$ release characteristics compared to the substrates containing strontianite only. This indicates that the release of $\mathrm{Sr}^{2+}$ ions was diffusion limited under these solution conditions. Yet, interestingly, the $D$. labyrinthiformis larvae did discriminate between the strontianite and the dolomite/strontianite substrates during settlement, showing a significant preference for the substrates containing strontianite only (Fig. 5b).

\section{Coral Larval Attraction is Mediated by lon Release and Surface Recognition}

Scanning electron microscopy of substrates containing quartz sand, strontianite, and dolomite/strontianite revealed similar general surface morphology (Fig. 8c). However, important local topographical differences were observed between strontianite and dolomite/strontianite substrates. Clusters of needle-like aragonite crystals were distributed across the surface of the strontianite substrates (Fig. 8d). Conversely, no aragonitic needle clusters were observed on the surfaces of dolomite/strontianite substrates, which contained 3.5x less aragonite in total (by PXRD; Fig. S6). We also observed large ( 20$50 \mu \mathrm{m}$ ) rhombohedral dolomite crystals on the surfaces of dolomite/strontianite substrates (Fig. 8e). These results suggest that the differences in local surface features may have been responsible for the preference of $D$. labyrinthiformis for strontianite substrates over dolomite/strontianite substrates, despite their similar $\mathrm{Sr}^{2+}$ release rates.

Although it is unclear whether the larvae were perhaps attracted to the needle-like aragonitic deposits in the strontianite substrates (which had a crystal morphology distinct from the aragonite sand additive; Fig. S1) or repelled by the large dolomite crystals in the dolomite/strontianite substrates, this high degree of selectivity in response to substrate composition and heterogeneity is consistent with that observed in the glass fiber experiment (Fig. 4). Therefore, given the preference of $D$. labyrinthiformis for substrates containing strontianite but not strontianite/dolomite, we propose a two-step mechanism of attraction may be at work: (1) larvae sense $\mathrm{Sr}^{2+}$ ions in the water column and are drawn to their source; (2) subsequently, larvae probe local surface features (aragonite needles or dolomite rhombohedrals) and choose their preferred settlement location based on micro-scale topography and heterogeneity and/or material composition. These surface recognition mechanisms may have also played a role in the preference of $A$. palmata and $D$. labyrinthiformis larvae for substrates containing quartz sand. However, given the selection of substrates we used, we could not resolve whether the preference for quartz sand resulted from the features of the substrate surface itself or by the release of silicates into the water column. Nevertheless, these experiments demonstrate the remarkable degree of specificity with which coral larvae choose a settlement substrate and the importance of inorganic substrate composition and micro-scale topography for larval settlement in general. 


\section{Conclusions}

Most research into the settlement of marine invertebrate larvae to date has focused on the effect of biochemical cues and larva-sized topographical features on larval substrate preferences. Here, we show that the inorganic composition and micro-scale topography of substrate materials can also strongly influence the settlement of larvae of two Caribbean coral species. The settlement of $A$. palmata and $D$. labyrinthiformis larvae on lime mortar substrates with lower glass fiber content demonstrates that larvae are sensitive to micrometer-scale substrate heterogeneities even when these do not modify average surface parameters such as mean roughness and surface area. Notably, these surface features created by exposed glass fibers were also more than an order of magnitude smaller than the topographical features expected to modify larval settlement preference according to Attachment Point Theory. We therefore suggest that Attachment Point Theory could be extended to consider composite substrates, and that perhaps new quantitative metrics are needed to better assess and compare localized surface features. Additional experiments with several inorganic additives reinforced our finding that coral larvae are remarkably sensitive to such micro-scale surface features while also revealing that larvae display speciesspecific attraction to particular materials: both $A$. palmata and D. labyrinthiformis responded to a quartzrich sand, while only $D$. labyrinthiformis responded to strontianite $\left(\mathrm{SrCO}_{3}\right)$. We propose that these attractions are mediated by the release of ions into the water column, which are then sensed by swimming larvae as they navigate towards substrates for further investigation of their settlement suitability.

Our findings help to highlight the hidden and under-recognized layers of interaction that exist in the already complex ecological process of coral larval recruitment. Fortunately, this complexity also creates opportunity: materials scientists and engineers can develop new tools that can be harnessed by restoration practitioners to rebuild coral communities and other threatened aquatic ecosystems. We hope our results will stimulate new research into understanding inorganic and materials-based cues for larval settlement and thus bolster efforts in materials engineering for coral reef restoration.

\section{Acknowledgements}

The authors acknowledge the National Science Foundation (NSF) for funding through the Convergence RAISE program (Award \# IOS-1848671) and the Government of Curaçao Ministry of Health, Environment, and Nature (GMN) for research and collecting permits provided to CARMABI. Z.A.Q. was supported by the NSF Graduate Research Fellowship Program (Award \# DGE-1842470). Coral spawning research at CARMABI in 2019 was also supported by the Paul G. Allen Family Foundation (to K.L.M.). Substrate characterization was carried out in part in the Materials Research Laboratory (MRL) Central Research Facilities, University of Illinois. The authors thank MRL scientists Dr. Julio Soares, Dr. Kathy Walsh, and Dr. Offir Cohen for their assistance and advice. We thank Dr. Valérie Chamberland and Kelly Latijnhouwers of SECORE International for the collection of $A$. palmata gametes and for their general support and ever helpful discussions. The authors also thank Dr. Alice Webb for providing the local seawater data used in the solubility model. Finally, we would like to thank others at CARMABI who assisted us during the 2019 spawning season including Matthew-James Bennett, Evan Culbertson, Tonia Doblado Speck, Daisy Flores, Nina Le Trocquer, Megan Ramirez, Zach Ransom, Sophie Schönherr, and the staff of The Diveshop Curaçao. 


\section{Author Contributions}

M.A.L., L.T., S.S., Z.A.Q., H.M.T, M.J.A.V., K.L.M., and A.J.W.J. conducted coral gamete collection dives. M.A.L., L.T., S.S., Z.A.Q., H.M.T, G.J., K.L.M., and A.J.W.J. participated in larval rearing and care. M.A.L. developed the lime mortar-based substrates, and M.A.L., H.M.T., and A.J.W.J. performed substrate fabrication. M.A.L., L.T., K.L.M., and A.J.W.J. conducted larval settlement experiments. M.A.L. performed substrate characterization and data analysis. J.Y. performed additional substrate characterization. I.L. performed gas sorption measurements and pore size modelling. M.A.L. and Z.A.Q. performed statistical analysis. K.L.M., M.J.A.V., and A.J.W.J. conceived of and supervised the project. G.J., L.W.K., K.L.M., M.J.A.V, and A.J.W.J acquired funding. M.A.L., K.L.M., and A.J.W.J. interpreted the results and wrote the paper with contributions from all authors.

\section{References}

1. Spalding, M.; Burke, L.; Wood, S. A.; Ashpole, J.; Hutchison, J.; zu Ermgassen, P., Mapping the global value and distribution of coral reef tourism. Marine Policy 2017, 82, 104-113.

2. Cesar, H.; Burke, L.; Pet-Soede, L. The economics of worldwide coral reef degradation; Cesar Environmental Economics Eonsulting (CEEC): 2003.

3. Bruckner, A. W., Life-Saving Products from Coral Reefs. Issues in Science and Technology 2002, 18 (3).

4. Gordon, T. A. C.; Radford, A. N.; Simpson, S. D.; Meekan, M. G., Marine restoration projects are undervalued. Science 2020, 367 (6478), 635.

5. Hughes, T. P.; Baird, A. H.; Bellwood, D. R.; Card, M.; Connolly, S. R.; Folke, C.; Grosberg, R.; Hoegh-Guldberg, O.; Jackson, J. B. C.; Kleypas, J.; Lough, J. M.; Marshall, P.; Nyström, M.; Palumbi, S. R.; Pandolfi, J. M.; Rosen, B.; Roughgarden, J., Climate Change, Human Impacts, and the Resilience of Coral Reefs. Science 2003, 301 (5635), 929.

6. Zaneveld, J. R.; Burkepile, D. E.; Shantz, A. A.; Pritchard, C. E.; McMinds, R.; Payet, J. P.; Welsh, R.; Correa, A. M. S.; Lemoine, N. P.; Rosales, S.; Fuchs, C.; Maynard, J. A.; Thurber, R. V., Overfishing and nutrient pollution interact with temperature to disrupt coral reefs down to microbial scales. Nature Communications 2016, 7, 11833.

7. Hughes, T. P.; Kerry, J. T.; Álvarez-Noriega, M.; Álvarez-Romero, J. G.; Anderson, K. D.; Baird, A. H.; Babcock, R. C.; Beger, M.; Bellwood, D. R.; Berkelmans, R.; Bridge, T. C.; Butler, I. R.; Byrne, M.; Cantin, N. E.; Comeau, S.; Connolly, S. R.; Cumming, G. S.; Dalton, S. J.; Diaz-Pulido, G.; Eakin, C. M.; Figueira, W. F.; Gilmour, J. P.; Harrison, H. B.; Heron, S. F.; Hoey, A. S.; Hobbs, J.-P. A.; Hoogenboom, M. O.; Kennedy, E. V.; Kuo, C.-y.; Lough, J. M.; Lowe, R. J.; Liu, G.; McCulloch, M. T.; Malcolm, H. A.; McWilliam, M. J.; Pandolfi, J. M.; Pears, R. J.; Pratchett, M. S.; Schoepf, V.; Simpson, T.; Skirving, W. J.; Sommer, B.; Torda, G.; Wachenfeld, D. R.; Willis, B. L.; Wilson, S. K., Global warming and recurrent mass bleaching of corals. Nature 2017, 543 (7645), 373-377.

8. Estrada-Saldívar, N.; Molina-Hernández, A.; Pérez-Cervantes, E.; Medellín-Maldonado, F.; González-Barrios, F. J.; Alvarez-Filip, L., Reef-scale impacts of the stony coral tissue loss disease outbreak. Coral Reefs 2020, 39 (4), 861-866.

9. Holbrook, S. J.; Adam, T. C.; Edmunds, P. J.; Schmitt, R. J.; Carpenter, R. C.; Brooks, A. J.; Lenihan, H. S.; Briggs, C. J., Recruitment Drives Spatial Variation in Recovery Rates of Resilient Coral Reefs. Scientific Reports 2018, 8 (1), 7338.

10. Cruz, D. W. d.; Harrison, P. L., Enhanced larval supply and recruitment can replenish reef corals on degraded reefs. Scientific Reports 2017, 7 (1), 13985. 
11. Richmond, R. H., Energetics, competency, and long-distance dispersal of planula larvae of the coral Pocillopora damicornis. Marine Biology 1987, 93 (4), 527-533.

12. Ritson-Williams, R.; Arnold, S. N.; Fogarty, N. D.; Steneck, R. S.; Vermeij, M. J. A.; Paul, V. J., New perspectives on ecological mechanisms affecting coral recruitment on reefs. Smithsonian Contributions to the Marine Sciences 2009, 38, 437-457.

13. Akiva, A.; Neder, M.; Kahil, K.; Gavriel, R.; Pinkas, I.; Goobes, G.; Mass, T., Minerals in the presettled coral Stylophora pistillata crystallize via protein and ion changes. Nature Communications 2018, 9, 1880 .

14. Hughes, T. P.; Tanner, J. E., Recruitment Failure, Life Histories, and Long-Term Decline of Caribbean Corals. Ecology 2000, 81 (8), 2250-2263.

15. Vermeij, M. J. A.; Bakker, J.; Hal, N. v. d.; Bak, R. P. M., Juvenile Coral Abundance Has Decreased by More Than 50\% in Only Three Decades on a Small Caribbean Island. Diversity 2011, 3 (3), 296-307.

16. Boström-Einarsson, L.; Babcock, R. C.; Bayraktarov, E.; Ceccarelli, D.; Cook, N.; Ferse, S. C. A.; Hancock, B.; Harrison, P.; Hein, M.; Shaver, E.; Smith, A.; Suggett, D.; Stewart-Sinclair, P. J.; Vardi, T.; McLeod, I. M., Coral restoration - A systematic review of current methods, successes, failures and future directions. PLOS ONE 2020, 15 (1), e0226631.

17. Randall, C. J.; Negri, A. P.; Quigley, K. M.; Foster, T.; Ricardo, G. F.; Webster, N. S.; Bay, L. K.; Harrison, P. L.; Babcock, R. C.; Heyward, A. J., Sexual production of corals for reef restoration in the Anthropocene. Marine Ecology Progress Series 2020, 635, 203-232.

18. Morse, D. E.; Hooker, N.; Morse, A. N. C.; Jensen, R. A., Control of larval metamorphosis and recruitment in sympatric agariciid corals. Journal of Experimental Marine Biology and Ecology 1988, 116 (3), 193-217.

19. Negri, A.; Webster, N.; Hill, R.; Heyward, A., Metamorphosis of broadcast spawning corals in response to bacteria isolated from crustose algae. Marine Ecology Progress Series 2001, 223, 121-131.

20. Tebben, J.; Motti, C. A.; Siboni, N.; Tapiolas, D. M.; Negri, A. P.; Schupp, P. J.; Kitamura, M.; Hatta, M.; Steinberg, P. D.; Harder, T., Chemical mediation of coral larval settlement by crustose coralline algae. Scientific Reports 2015, 5, 10803.

21. Golbuu, Y.; Richmond, R. H., Substratum preferences in planula larvae of two species of scleractinian corals, Goniastrea retiformis and Stylaraea punctata. Marine Biology 2007, 152 (3), 639644.

22. Mason, B.; Beard, M.; Miller, M. W., Coral larvae settle at a higher frequency on red surfaces. Coral Reefs 2011, 30 (3), 667-676.

23. Marhaver, K. L.; Vermeij, M. J. A.; Medina, M. M., Reproductive natural history and successful juvenile propagation of the threatened Caribbean Pillar Coral Dendrogyra cylindrus. BMC Ecology 2015, $15,9$.

24. Chamberland, V. F.; Vermeij, M. J. A.; Brittsan, M.; Carl, M.; Schick, M.; Snowden, S.; Schrier, A.; Petersen, D., Restoration of critically endangered elkhorn coral (Acropora palmata) populations using larvae reared from wild-caught gametes. Global Ecology and Conservation 2015, 4, 526-537.

25. Hartmann, A. C.; Marhaver, K. L.; Chamberland, V. F.; Sandin, S. A.; Vermeij, M. J. A., Large birth size does not reduce negative latent effects of harsh environments across life stages in two coral species. Ecology 2013, 94 (9), 1966-1976.

26. Ritson-Williams, R.; Arnold, S. N.; Paul, V. J., Patterns of larval settlement preferences and post-settlement survival for seven Caribbean corals. Marine Ecology Progress Series 2016, 548, 127-138.

27. Chamberland, V. F.; Snowden, S.; Marhaver, K. L.; Petersen, D.; Vermeij, M. J. A., The reproductive biology and early life ecology of a common Caribbean brain coral, Diploria labyrinthiformis (Scleractinia: Faviinae). Coral Reefs 2017, 36 (1), 83-94.

28. Morse, D. E.; Aileen, N. C. M., Enzymatic Characterization of the Morphogen Recognized by Agaricia humilis (Scleractinian Coral) Larvae. Biological Bulletin 1991, 181 (1), 104-122. 
29. Heyward, A. J.; Negri, A. P., Natural inducers for coral larval metamorphosis. Coral Reefs 1999, 18 (3), 273-279.

30. Gómez-Lemos, L. A.; Doropoulos, C.; Bayraktarov, E.; Diaz-Pulido, G., Coralline algal metabolites induce settlement and mediate the inductive effect of epiphytic microbes on coral larvae. Scientific reports 2018, 8, 17557.

31. Morse, D. E.; Morse, A. N. C.; Raimondi, P. T.; Hooker, N., Morphogen-Based Chemical Flypaper for Agaricia humilis Coral Larvae. The Biological Bulletin 1994, 186 (2), 172-181.

32. Aileen, N. C. M.; Iwao, K.; Baba, M.; Shimoike, K.; Hayashibara, T.; Omori, M., An Ancient Chemosensory Mechanism Brings New Life to Coral Reefs. Biological Bulletin 1996, 191 (2), 149-154.

33. Vermeij, M. J. A.; Marhaver, K. L.; Huijbers, C. M.; Nagelkerken, I.; Simpson, S. D., Coral Larvae Move toward Reef Sounds. PLOS ONE 2010, 5 (5), e10660.

34. Gleason, D. F.; Edmunds, P. J.; Gates, R. D., Ultraviolet radiation effects on the behavior and recruitment of larvae from the reef coral Porites astreoides. Marine Biology 2006, 148 (3), 503-512.

35. Fuchs, H. L.; Gerbi, G. P.; Hunter, E. J.; Christman, A. J.; Diez, F. J., Hydrodynamic sensing and behavior by oyster larvae in turbulence and waves. The Journal of Experimental Biology 2015, 218 (9), 1419-1432.

36. Walters, L. J.; Wethey, D. S., Settlement, Refuges, and Adult Body Form in Colonial Marine Invertebrates: A Field Experiment. The Biological Bulletin 1991, 180 (1), 112-118.

37. Myan, F. W. Y.; Walker, J.; Paramor, O., The interaction of marine fouling organisms with topography of varied scale and geometry: a review. Biointerphases 2013, 8, 30.

38. Erramilli, S.; Genzer, J., Influence of surface topography attributes on settlement and adhesion of natural and synthetic species. Soft Matter 2019, 15 (20), 4045-4067.

39. Carl, C.; Poole, A. J.; Sexton, B. A.; Glenn, F. L.; Vucko, M. J.; Williams, M. R.; Whalan, S.; de Nys, R., Enhancing the settlement and attachment strength of pediveligers of Mytilus galloprovincialis bychanging surface wettability and microtopography. Biofouling 2012, 28 (2), 175-186.

40. Vucko, M. J.; Poole, A. J.; Carl, C.; Sexton, B. A.; Glenn, F. L.; Whalan, S.; de Nys, R., Using textured PDMS to prevent settlement and enhance release of marine fouling organisms. Biofouling 2014, 30 (1), 1-16.

41. Whalan, S.; Wahab, M. A. A.; Sprungala, S.; Poole, A. J.; de Nys, R., Larval Settlement: The Role of Surface Topography for Sessile Coral Reef Invertebrates. Plos One 2015, 10 (2), e0117675.

42. Callow, M. E.; Jennings, A. R.; Brennan, A. B.; Seegert, C. E.; Gibson, A.; Wilson, L.; Feinberg, A.; Baney, R.; Callow, J. A., Microtopographic Cues for Settlement of Zoospores of the Green Fouling Alga Enteromorpha. Biofouling 2002, 18 (3), 229-236.

43. Scardino, A. J.; Harvey, E.; De Nys, R., Testing attachment point theory: diatom attachment on microtextured polyimide biomimics. Biofouling 2006, 22 (1), 55-60.

44. Siddik, A. A.; Satheesh, S., Interactive effects of light and substrate colour on the recruitment of marine invertebrates on artificial materials. Community Ecology 2021, 22 (1), 69-78.

45. Noburu, S.; Euichi, H., Wettability and Substrate Selection in the Larval Settlement of the Solitary Ascidian Phallusia philippinensis (Phlebobranchia: Ascidiidae). Zoological Science 2020, 37 (4), 366-370.

46. Burt, J.; Bartholomew, A.; Bauman, A.; Saif, A.; Sale, P. F., Coral recruitment and early benthic community development on several materials used in the construction of artificial reefs and breakwaters. Journal of Experimental Marine Biology and Ecology 2009, 373 (1), 72-78.

47. Siddik, A. A.; Al-Sofyani, A. A.; Ba-Akdah, M. A.; Satheesh, S., Invertebrate recruitment on artificial substrates in the Red Sea: role of substrate type and orientation. Journal of the Marine Biological Association of the United Kingdom 2019, 99 (4), 741-750.

48. Kennedy, E. V.; Ordonez, A.; Lewis, B. E.; Diaz-Pulido, G., Comparison of recruitment tile materials for monitoring coralline algae responses to a changing climate. Marine Ecology Progress Series 2017, 569, 129-144. 
49. Antink, M. M. H.; Ropke, L.; Bartels, J.; Soltmann, C.; Kunzmann, A.; Rezwan, K.; Kroll, S., Porous ceramics with tailored pore size and morphology as substrates for coral larval settlement. Ceramics International 2018, 44 (14), 16561-16571.

50. Richmond, R. H.; Hunter, C. L., Reproduction and recruitment of corals: comparisons amoung the Caribbean, the Tropical Pacific, and the Red Sea. Marine Ecology Progress Series 1990, 60, 185-203.

51. Vermeij, M. J. A.; Fogarty, N. D.; Miller, M. W., Pelagic conditions affect larval behavior, survival, and settlement patterns in the Caribbean coral Montastraea faveolata. Marine Ecology Progress Series 2006, 310, 119-128.

52. Hansen, E. F.; Rodriguez-Navarro, C.; Van Balen, K., Lime Putties and Mortars: Insights into Fundamental Properties. Stud. Conserv. 2008, 53 (1), 9-23.

53. Rustom, L. E.; Boudou, T.; Lou, S.; Pignot-Paintrand, I.; Nemke, B. W.; Lu, Y.; Markel, M. D.; Picart, C.; Wagoner Johnson, A. J., Micropore-induced capillarity enhances bone distribution in vivo in biphasic calcium phosphate scaffolds. Acta Biomaterialia 2016, 44, 144-154.

54. Armstrong, A. A.; Norato, J.; Alleyne, A. G.; Johnson, A. J. W., Direct process feedback in extrusion-based 3D bioprinting. Biofabrication 2019, 12 (1), 015017.

55. McDonald, J. C.; Whitesides, G. M., Poly(dimethylsiloxane) as a material for fabricating microfluidic devices. Accounts of Chemical Research 2002, 35 (7), 491-499.

56. Webster, N. S.; Smith, L. D.; Heyward, A. J.; Watts, J. E. M.; Webb, R. I.; Blackall, L. L.; Negri, A. P., Metamorphosis of a Scleractinian Coral in Response to Microbial Biofilms. Applied and Environmental Microbiology 2004, 70 (2), 1213-1221.

57. Benjamini, Y.; Hochberg, Y., Controlling the False Discovery Rate: A Practical and Powerful Approach to Multiple Testing. Journal of the Royal Statistical Society. Series B (Methodological) 1995, 57 (1), 289-300.

58. Doebelin, N.; Kleeberg, R., Profex: a graphical user interface for the Rietveld refinement program BGMN. Journal of Applied Crystallography 2015, 48 (5), 1573-1580.

59. Millero, F. J.; Feistel, R.; Wright, D. G.; McDougall, T. J., The composition of Standard Seawater and the definition of the Reference-Composition Salinity Scale. Deep Sea Research Part I: Oceanographic Research Papers 2008, 55 (1), 50-72.

60. Quinby-Hunt, M. S.; Turehian, K. K., Distribution of elements in sea water. Eos, Transactions American Geophysical Union 1983, 64 (14), 130-132.

61. Chamberland, V. F.; Petersen, D.; Guest, J. R.; Petersen, U.; Brittsan, M.; Vermeij, M. J. A., New Seeding Approach Reduces Costs and Time to Outplant Sexually Propagated Corals for Reef Restoration. Scientific Reports 2017, 7 (1), 18076.

62. Sepulveda, P.; Jones, J. R.; Hench, L. L., In vitro dissolution of melt-derived $45 \mathrm{~S} 5$ and sol-gel derived $58 \mathrm{~S}$ bioactive glasses. Journal of Biomedical Materials Research 2002, 61 (2), 301-311.

63. Levenstein, M. A.; Anduix-Canto, C.; Kim, Y.-Y.; Holden, M. A.; González Niño, C.; Green, D. C.; Foster, S. E.; Kulak, A. N.; Govada, L.; Chayen, N. E.; Day, S. J.; Tang, C. C.; Weinhausen, B.; Burghammer, M.; Kapur, N.; Meldrum, F. C., Droplet Microfluidics XRD Identifies Effective Nucleating Agents for Calcium Carbonate. Advanced Functional Materials 2019, 29, 1808172.

64. Sun, W.; Jayaraman, S.; Chen, W.; Persson, K. A.; Ceder, G., Nucleation of metastable aragonite CaCO3 in seawater. Proceedings of the National Academy of Sciences 2015, 112 (11), 3199-3204.

65. Mass, T.; Giuffre, A. J.; Sun, C.-Y.; Stifler, C. A.; Frazier, M. J.; Neder, M.; Tamura, N.; Stan, C. V.; Marcus, M. A.; Gilbert, P. U. P. A., Amorphous calcium carbonate particles form coral skeletons. Proceedings of the National Academy of Sciences 2017, 114 (37), E7670-E7678.

66. Sunagawa, I.; Takahashi, Y.; Imai, H., Strontium and aragonite-calcite precipitation. Journal of Mineralogical and Petrological Sciences 2007, 102 (3), 174-181. 
67. Randall, C. J.; Szmant, A. M., Elevated Temperature Affects Development, Survivorship, and Settlement of the Elkhorn Coral, Acropora palmata (Lamarck 1816). The Biological Bulletin 2009, 217 (3), 269-282.

68. Henderson, J. R., Statistical mechanics of Cassie's law. Molecular Physics 2000, 98 (10), 677-681.

69. Crundwell, F. K., On the Mechanism of the Dissolution of Quartz and Silica in Aqueous Solutions. ACS Omega 2017, 2 (3), 1116-1127.

70. Uchida, H.; Kawano, T.; Aoyama, M.; Murata, A., Absolute salinity measurements of standard seawaters for conductivity and nutrients. La mer 2011, 49, 119-126. 